\title{
Economic and financial determinants of firm bankruptcy: evidence from the French food industry
}

\author{
Lilia Aleksanyan $^{1,2}$ • Jean-Pierre Huiban ${ }^{2,3}$
}

Received: 16 June 2014 / Accepted: 17 February 2016 / Published online: 13 June 2016

(C) INRA and Springer-Verlag France 2016

\begin{abstract}
Despite the strong resilience of the French food industry during the recent economic crisis, the bankruptcy rate for this sector has dramatically increased since 2010 . This paper focuses on the economic and financial determinants of firm exit due to bankruptcy in the French food industry and compares them with those for other manufacturing industries. Based on a large sample of firm-level data for the period 2001-2012, we show that the bankruptcy risk pattern differs between food industry firms and other manufacturing firms. Firm productivity is an important determinant of a firm's probability of going bankrupt; productivity begins deteriorating 3 years before a failure. Controlling for firm productivity, we also show that credit cost has a positive and significant impact on the probability of bankruptcy. However, we observe smaller effect of credit cost on firms' bankruptcy risk. In contrast, productivity appears to have an important beneficial effect on bankruptcy risk reduction.
\end{abstract}

Keywords Firm exit · Firm bankruptcy $\cdot$ Cost of credit . Productivity $\cdot$ Food industry

JEL Classification G33 · G21 · D24

The main part of this paper was written when Lilia Aleksanyan was working at the Banque de France.

Lilia Aleksanyan

lilia.aleksanyan@gmail.com

Université Paris 1 Panthéon Sorbonne, F-75000 Paris, France

2 INRA UR1303 ALISS, F-94205 Ivry-sur-Seine, France

3 Université Paris-Est Créteil, F-94000 Créteil, France

\section{Introduction}

Every year in France, more than 3500 manufacturing companies file for bankruptcy (Stat Info 2013), of which nearly one third are declared in the food industries. ${ }^{1}$ The French food industries demonstrated considerable resiliency compared to the manufacturing industry during the recent economic crisis (Aleksanyan 2015). According to Fougère et al. (2013), nearly half of the failures during the period 2008-2010 in the French manufacturing industry can be attributed to the crisis. However, the crisis peak of bankruptcies that occurred in the manufacturing industry was not observed in the food industry. Indeed, according to data from the Banque de France and our calculations, the annual bankruptcy rate was approximately $2.7 \%^{2}$ in 2009 in the manufacturing industry compared with $0.8 \%$ in the food industry. This disparity is often explained by the inertia of household food and beverage consumption, which supported firm activity during the crisis. However, this situation deteriorated over the period between 2010 and 2012 for food industry firms, and the French food industry has reported a dramatic increase in bankruptcy cases. ${ }^{3}$ The bankruptcy rate of the food industries nearly doubled between 2010 and 2012 (Fig. 1).

Some of these bankruptcies concerned large and economically important business units and reflected the increasing difficulties confronting the French food industries. For example, the group Doux, one of the French leaders in processing and preserving poultry, declared bankruptcy in 2012; GAD Ltd. (slaughterhouses, cutting and processing pork) filed for bankruptcy at the beginning of 2013; it was announced in

\footnotetext{
${ }^{1}$ In this paper, food industries refer to the manufacture of food products, beverages, and tobacco products (agrifood industries) including the manufacture of bakery and farinaceous products.

${ }^{2}$ See Appendix for details about the computation method.

${ }^{3}$ See Table 7 in Appendix.
} 


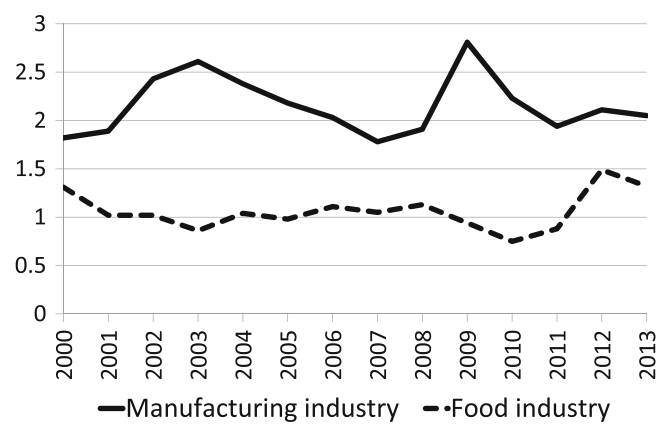

Fig. 1 Bankruptcy rate, \%. Source: Firms' balance sheets' and bankruptcies' databases (Banque de France) and authors' calculations

2014 that two French subsidiaries of the international seafood group Marine Harvest would be closed down; and TillySabco, a company operating in the chicken-slaughtering business that produces chicken-based sausages, repeatedly experienced bankruptcy risk in 2013. The primary difficulties mentioned by the food companies' leaders and food industry experts are related to rising commodity prices, unequal negotiating power with retail trade groups with respect to setting product prices or quantities, the reduction of European subsidies, especially for the poultry meat industries, and competitiveness issues in the European market for certain industries (e.g., low labor costs for German slaughterhouses relative to French slaughterhouses). The macroeconomic environment and demand-side factors could also underlie the increase in firm bankruptcies in the food industry during the period 2010 2012. For example, according to the National Institute of Statistics and Economic Studies (INSEE), ${ }^{4}$ the growth rate of exports for food and beverages decreased considerably after 2010. In addition to this decrease in exports, the domestic market also faced lower food demand: household food consumption growth declined after 2010 in contrast to almost $2 \%$ growth during the period between 2009 and 2010.

The aim of this study is to analyze the impact of economic and financial factors at the firm level on bankruptcy risk in the French food industry and other manufacturing industries. Firm bankruptcy is defined as the initiation of judicial reorganization or liquidation proceedings, equivalent to the bankruptcy definition stipulated by the French law. Bankruptcy follows payment default or a situation in which the debtor company becomes unable to repay its debts. Although bankruptcy is part of the market selection process and can be considered to be the consequence of a firm's inability to survive market competition, it may entail multiple damaging repercussions, occasionally of significant scale, in terms of job losses, the destruction of assets, and of a productive base. For example, according to our calculations, over the period 2001-2012, the economic impact of French food industry bankruptcies was equivalent to an average of nearly 2700 jobs each year

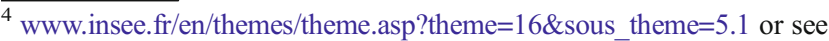
Appendix, Fig. 3.
}

(the peak was in 2012, when more than 4000 jobs were affected by food industry bankruptcies). ${ }^{5}$

The aim of this paper is to understand the evolution of firms' bankruptcy risk and to identify the determinants of exits due to bankruptcy. The size and age of firms are considered to be the primary factors affecting bankruptcy risk: smaller or younger firms are the most likely to file for bankruptcy. Firms' bankruptcy risk is also related to their economic performance, the macroeconomic environment, and financing conditions. Indeed, the hypothesis is that firms' exits are not only linked to their inefficiency. Firms' financing conditions also can play a role in the market selection process. Difficulties in obtaining access to credit or banks' tight credit standards for firms can challenge these firms' survival and become a cause of exit. Therefore, firms with better access to credit or those that obtain favorable credit covenants will have a greater probability of survival. Moreover, even highly productive firms may be forced to exit the market if they are credit constrained or if the cost of credit is excessive. The issues related to financing conditions are particularly relevant in the context of the recent crisis for two reasons. First, debtor interest rates for several categories of bank loans to nonfinancial corporations changed slightly before, during, and after the recent crisis, ${ }^{6}$ with a significant increase in the heterogeneity of lending conditions to firms (e.g., Avouyi-Dovi et al. 2012). Second, the crisis may have induced credit rationing by deteriorating the financing conditions faced by firms. Indeed, in the context of an increased risk level, banks may become more restrictive in granting credits to firms and thereby deteriorate firms' access to credit. However, Kremp and Sevestre (2013) show that French small- and medium-sized enterprises (SMEs) have not been strongly affected by credit rationing after the 2008 crisis.

This study conducts an analysis of firm bankruptcy by accounting for productivity-linked factors and firm financial factors. Our model is based on Ericson and Pakes (1995) and Olley and Pakes (1996), as well as on recent developments in Blanchard et al. (2012). In addition to the theoretical considerations proposed in these papers, we also consider the financing conditions faced by firms as one of the determinants of firm exit. Based on this framework, our study analyses a firm's decision to exit if, given its capital stock, its productivity shock, its debt level, its cost of credit and its environment at a given moment, it is more profitable to go bankrupt and get the value of bankruptcy (i.e., the assets that remain to the firm after bankruptcy proceeding) than to keep going and obtain

\footnotetext{
${ }^{5}$ To calculate these statistics, we used the data from the bankrupt firms' most recent available balance sheet information in the Banque de France databases up to 3 years before the bankruptcy.

${ }^{6}$ One of the reasons is that at the end of 2008, the European Central Bank significantly reduced its main refinancing operations rate which in turn triggered a decrease in the cost of bank loans to non-financial corporations.
} 
the expected profits from continued operations. The empirical part of our study provides an evidence on firms' exit behavior due to bankruptcy based on these theoretical considerations. ${ }^{7}$ Based on a rich microeconomic data set comprising firm balance sheet information merged with the firm bankruptcy recordings database during the period 2001-2012, our econometric analysis concentrates on firms' bankruptcies in the French food industry and compares them with other manufacturing firms.

This paper is organized as follows. First, we outline the general theoretical framework and selected findings from the relevant literature on firm exit. The economic model is presented in the subsequent section. Then, we present the dataset and the main descriptive statistics. The final section presents our econometric specification and the estimation results and is followed by conclusions.

\section{A brief literature review}

The importance of firm demography in explaining aggregate economic outcomes such as growth, productivity, and innovation has long been recognized. Since the 1980 s, as more microeconomic data on firms' lifetime trajectories (including firm entry and exit) have become available, firm demography has attracted greater interest from applied economists and econometricians. The main findings concern firm mobility as a key condition to the evolution of aggregate productivity, the level of competitiveness, and the propensity to innovate at a country or industry level. Indeed, on average, exiting (entrant) firms are less (more) productive than incumbents. Therefore, firm mobility (i.e., exit and entry) contributes to the reallocation of resources and to the growth of aggregate productivity through turnover-induced productivity gains.

A well-documented stylized fact regarding firm mobility is the heterogeneity of firm behavior concerning the decision to exit (or to enter) the market (e.g., Roberts and Tybout 1997; Caves 1998; Bartelsman and Doms 2000). Jovanovic (1982) and Hopenhayn (1992) provide the first theoretical framework for firm mobility in the context of firm heterogeneity. The

\footnotetext{
${ }^{7}$ In this sense, our study differs from bankruptcy prediction literature based on discriminant analysis as in Altman (1968), the very first model to estimate probability of default using discriminant analysis. It turns out that discriminant analysis is equivalent to the linear probability model for a binary-dependent variable. Since the beginning of the 1980 s, researchers and practitioners also used logit and probit models to estimate probabilities of bankruptcies, as in the Riskcalc models. The objective of these methods is to predict bankruptcy occurrence or quantitatively evaluate bankruptcy risk using different financial and non-financial ratios that best discriminates healthy firms from bankrupt firms. The methodological approach of our study is based on our theoretical considerations on firms' exit behavior due to bankruptcy. Thus, our objective is to investigate the causes of bankruptcy within our theoretical framework and does not consider discriminant analysis to model bankruptcy prediction.
}

learning model advanced by Jovanovic (1982) suggests that firms enter the industry without knowing their productive efficiency. Only after a certain period of time is their efficiency revealed, and eventually, they decide either to stay or to exit the sector if their efficiency is low. This notion of endogenous exit was subsequently extended in the model developed by Hopenhayn (1992) in a more general framework of industrial equilibrium, taking into account the firms' exogenous characteristics (exogenous productivity shocks, the entry cost, aggregate demand, etc.).

Ericson and Pakes (1995) more precisely exploit this idea of firm heterogeneity in modeling the firm exit decision. Firms differ according to their realized state of success or efficiency level. A high level of firm efficiency indicates its stronger position relative to its competitors and to potential entrants. According to Ericson and Pakes (1995), firm efficiency depends, among other factors, on the return of firm investment. In other words, to obtain high levels of efficiency, firms must invest. Therefore, they select an investment level that maximizes their expected discounted profit. Next, firms compare the value of their expected discounted profit with the opportunity cost of remaining (e.g., sell-off value) and decide whether to exit or to continue their activity. Thus, Ericson and Pakes (1995) demonstrate that both the investment level and the decision to exit depend on the level of firm efficiency. Ericson and Pakes' (1995) model was further reconsidered by Olley and Pakes (1996) in an empirical framework. Based on plant-level data, they demonstrate that the probability of exit depends on firm efficiency.

The models introduced by Jovanovic (1982) and Ericson and Pakes (1995) implicitly assume that firms' financial situations have no impact on exit decisions. However, recent studies, especially in the field of firm dynamics (including firm exit), consider the role of credit market frictions and/or financing constraints (e.g., Cooley and Quadrini 2001; Osotimehin and Pappadà 2015; Arellano et al. 2012) and Albuquerque and Hopenhayn 2004). The "toy" model considering the role of financial constraints in the context of firm dynamics is based on Evans and Jovanovic (1989). In particular, these authors provide a model of firm creation in the presence of liquidity constraints. Extending Hopenhayn's (1992) model, Cooley and Quadrini (2001) propose a specification of firm dynamics that takes the firms' financing constraints into account. The general premise of their study is that by controlling for firm age and size, the financial frictions impact on firm dynamics, including on firms' exit. These authors consider an exogenous exit, i.e., firms become unproductive and exit. Osotimehin and Pappadà (2015) follow Cooley and Quadrini (2001) but consider endogenous exit. According to their model, firm selection is influenced by imperfections in the credit market: productive units can be forced to exit due to credit constraints, whereas unproductive units can survive. Thus, in the presence of financial frictions, firms may decide to exit due to credit 
rationing (for example, the firm is unable to cover its fixed costs and opts to exit).

The primary empirical evidence supports the notion that firm efficiency and the probability of exit are negatively related. The following list of studies is not exhaustive. Baily et al. (1992) show that the probability of firm death is high among firms with low levels of productivity. Following a different methodology, Dwyer (1998) shows that firms at the bottom of the productivity distribution have the highest exit rates. Fariñas and Ruano (2005) also show that firms' exit behavior reflects the initial productivity heterogeneity, and hence, higher productivity will reduce firms' exit probability. Based on French firm-level data, Bellone et al. (2006) show that the closer firms are to their exit year, the lower their productivity is. Blanchard et al. (2012) also use French firmlevel data (in the food industry) covering the period 19962002 and show that productivity has a negative and significant impact on firm exit probability. Based on the French data, Boyer and Blazy (2014) consider among others the firms' financing characteristic effect on survival. They show that sources of financing (personal financing as well as bank financing) have a positive effect on survival.

\section{The economic model}

Our model is based on Ericson and Pakes (1995), Olley and Pakes (1996), Ackerberg et al. (2007), as well as on recent developments in Blanchard et al. (2012). We consider an endogenous exit model, i.e., the firm's optimal choice could be to abandon its entrepreneurial project and exit the industry. Firm success (or profitability, value, etc.) depends on several factors, such as investments. At each period $t$, a firm with a productivity level $\omega$ chooses its investment level such that it maximizes its expected discounted profits.

Following Olley and Pakes (1996), we define the firm production function as follows:

$y_{i t}=\beta_{0}+\beta_{k} k_{i t}+\beta_{l} l_{i t}+\beta_{a} a_{i t}+\omega_{i t}+\eta_{i t}$

where $k$ is the capital, $l$ denominates labor, $a$ denotes firm age, $\eta_{i t}$ represents the factors that are unobservable by the firm $i$ and by the econometrician, and $\omega_{i t}$ is the firm-specific productivity observed by the firm $i$ but unobservable by the econometrician.

At each period, capital is defined on the basis of the capital accumulation rule

$k_{i t}=(1-\delta) k_{i t-1}+i_{i t}$

where $i_{i t}$ is firm investment in period $t$. According to this specification, capital is the non-flexible input. However, labor is considered to be a flexible input. Labor is chosen and used during period $t$.
We also assume that in each period, an active firm needs to invest, $I_{i t}$. If the investment exceeds the available internal resources, the firm will need to borrow, $B_{i t}$. The firm is granted a certain amount of one-period credit in each period, but it must repay it at the end of the period: $B_{R i t}=\left(1+r_{B i t}\right) B_{i t}$, where $r_{B}$ is the interest rate fixed by the bank. At this stage, we assume that there is no credit rationing.

At each period, a firm's profit is defined as follows:

$\pi_{i t}=R\left(K_{i t}, a_{i t}, \omega_{i t}, \gamma_{t}\right)-\left(1+r_{B i t}\right) B_{i t}$

where $R\left(K_{i t}, a_{i t}, \omega_{i t}, \gamma_{t}\right)$ is the firm's revenue, and $\gamma_{t}$ is firms' economic environment at period $t$ (for example, demand factors or the characteristics of the sector). ${ }^{8}$ One can regard this equation as a conditional profit function (conditional on the optimal choice of labor at period $t$ ).

In this framework, the exit decision can be modeled on the basis of a Bellman equation:

$$
\begin{aligned}
V\left(K_{i t}, a_{i t}, \omega_{i t}, r_{B i t}, B_{i t}, \gamma_{t}\right) & \\
& =\max \left\{\phi, \max _{i_{i t}}\left\{R\left(K_{i t}, a_{i t}, \omega_{i t}, \gamma_{t}\right)-\left(1+r_{B i t}\right) B_{i t}\right.\right. \\
& \left.\left.+\beta E\left[V\left(K_{i t+1}, a_{i t+1}, \omega_{i t+1}, r_{B i t+1}, B_{i t+1}, \gamma_{t+1}\right) \mid \Theta_{t}\right]\right\}\right\}
\end{aligned}
$$

where $\phi$ is the opportunity cost (or the value of bankruptcy for the firm), and $\Theta_{t}$ is the overall information available to the firm at time $t$. Thus, the firm decides to exit if, given its capital level $K_{i t}$, its productivity $\omega_{i t}$, the cost of credit $r_{B i t}$ and the amount of credit $B_{i t}$, the opportunity cost of remaining active is higher than the expected profit:

$$
\begin{aligned}
& \max _{i_{i t}} \\
& \left\{R\left(K_{i t}, a_{i t}, \omega_{i t}, \gamma_{t}\right)-\left(1+r_{B i t}\right) B_{i t}+\beta E\left[V\left(K_{i t+1}, a_{i t+1}, \omega_{i t+1}, r_{B i t+1}, B_{i t+1}, \gamma_{t+1}\right) \mid \Theta_{t}\right]\right\}
\end{aligned}
$$

Thus, the exit decision is based on a firm's comparison of expected discounted profits $(E D P)$ with a certain opportunity cost of staying, $\varnothing .^{9}$ The exit rule is as follows: if $\mathrm{EDP}<\phi$, the firm exits and receives $\phi$. If $\mathrm{EDP}>\phi$, the firm continues its activity and realizes the chosen level of investment, $I$.

Thus, we obtain the following decision rule for firm exit given certain assumptions ${ }^{10}$ :

$\chi_{i t}= \begin{cases}1(\text { stay }), & \text { if } \omega_{i t} \geq \underline{\omega}\left(K_{i t}, a_{i t}, r_{B i t}, B_{i t}, \gamma_{t}\right) \\ 0 \text { (exit), } & \text { otherwise }\end{cases}$

\footnotetext{
${ }^{8}$ Note that in this definition of profit, labor does not appear explicitly because labor is the flexible input.

${ }^{9}$ For example, here, in the event of exit due to bankruptcy, it can be the value of bankruptcy for the firm or the assets remaining with the firm after judicial proceedings.

${ }^{10}$ These assumptions are that the equilibrium exists and that the difference between expected profits and opportunity costs is increasing in productivity.
} 
where $\underline{\omega}\left(K_{i t}, a_{i t}, r_{B i t}, B_{i t}, \gamma_{t}\right)=\underline{\omega}_{t}\left(K_{i t}, a_{i t}, r_{B i t}, B_{i t}\right)$ is the productivity threshold at industry level (or country level) for firms with capital $K$, age $a$, cost of borrowing $r_{B i t}$, and amount of borrowed capital $B_{i t}$. In other words, the firm will continue its activity if its productivity is greater than a certain threshold level. Thus, first, the firm decides whether to exit. If the firm stays, it realizes investment $I$. We can now express the probability of exit as follows:

$$
\begin{array}{r}
P(\text { exit })=1-P(\text { stay })=1-P\left[\chi_{i t}=1 \mid \Theta_{i t}\right]=P\left[\omega_{i t} \geq \underline{\omega}_{t}\left(K_{i t}, a_{i t}, \omega_{i t}\right) \mid \Theta_{i t} t\right] \\
=1-P\left[\chi_{i t}=1 \mid \omega_{i t}, \underline{\omega}_{t}\left(K_{i t}, a_{i t}, r_{B i t}, B i t\right)\right] \\
=1-\widetilde{\phi}_{t}\left(\omega_{i t}, \underline{\omega}_{t}\left(K_{i t}, a_{i t}, r_{B i t}, B i t\right)\right) \\
=1-\phi\left(\omega_{i t}, K_{i t}, a_{i t}, r_{B i t}, B i t\right)
\end{array}
$$

Thus, the probability of exit will be as follows:

$P($ exit $)=f\left(\omega_{i t}, K_{i t}, a_{i t}, r_{B i t}, B_{i t}\right)$

According to this model, the firm's probability of exit depends on the capital level, firm age, productivity, and borrowing conditions (cost of credit and amount borrowed).

\section{Data description and descriptive statistics}

The sample is obtained by merging data from the Banque de France balance sheet database (Fiben Bilan) covering the period 1998-2012 and the firm bankruptcy database covering the period 2001-2013, also available from the Banque de France. Our analysis separately considers the food industry, the manufacturing industry excluding the food industry, and the entire manufacturing industry. Merging these two databases, we get a sample containing over 492,000 firm-year observations covering the period 2001-2012. This is an unbalanced panel data set with an average of approximately 35 , 000 manufacturing companies per year. Notably, the Fiben Bilan database includes a very small number of bankrupt firms (only approximately $0.5 \%$ of the total number of observations over the period 2001-2012). From 2001 to 2012, the French courts registered almost 4400 bankruptcies of manufacturing business units per year, but each year fewer than 250 of these bankrupt firms were in the balance sheet database the year of the failure, and nearly 1000 bankrupt firms were observed at most 3 years before the failure.

Our analysis is based on the following firm economic and financial characteristics. ${ }^{11}$ Firm productivity or total factor

\footnotetext{
${ }^{11}$ Our empirical modeling does not consider other firm risk-related variables as in the Altman (1968) modeling for two reasons. First, the inclusion of additional financial variables did not bring new information in the model, and we consider that firm debt structure and financial cost are good proxies to take into account firms' financial characteristics. Second, we assume that the firm size variable contains a lot of information on firm risk-related factors and there is no need to add new variables in the model.
}

productivity (TFP) is estimated at the establishment level as the residual of an estimated production function using labor, capital (tangible assets), and intermediate inputs as inputs and production level as the output. Our approach is based on the semi-parametric estimator proposed by Olley and Pakes (1996) and Levinsohn and Petrin (2003). According to this method, the observed input choices are used to instrument for the unobserved productivity to control for simultaneity bias and selection bias, as in the case of Olley and Pakes (1996). ${ }^{12}$ The simultaneity bias occurs because the firm has prior knowledge of its productivity level at the time that input decisions are made, and hence, the level of inputs chosen and unobserved productivity shocks are correlated. Selection bias occurs because certain firms survive over the period under consideration. In other words, the bias emerges from the fact that firms' input decisions are made conditional on their survival (non-exit) and firms' exit probability is related to their productivity level. Thus, because firms can have some knowledge of their productivity level prior to exit, the unobserved productivity and inputs will be correlated conditional on not exiting. By taking into account these methodological issues, production functions and TFP are estimated at the division level of the manufacturing sector according to the French classification of activities. ${ }^{13}$

The cost of credit is measured as the ratio of firms' financial charges over total debt. As bank credit is the main financing source for the firms in our sample, this variable is a better measure of the interest rate on bank credit. Bank debt on total assets is a proxy for firms' amount of external debt due. Our model also includes variables on firm age, the manufacturing activity sub-sector, and a size categorical variable based on firms' total assets.

Bankrupt firms have different characteristics than healthy firms (Table 1). Bankrupt firms are essentially SMEs (nearly $98 \%$ of our sample). As the prior evidence indicates, bankruptcy is a particular concern for small firms, especially due to their limited resistance to external shocks and their high level of operational and financial costs relative to large firms. Moreover, the bankruptcy rate is higher for independent SMEs, which suggests that independent SMEs are in a more vulnerable position than those with a financial linkage to a corporate group. Not surprisingly, a poor Banque de France rating is linked to reported bankruptcy cases. In particular, for the food industry, a high number of bankrupt firms had previously received a bad credit risk rating from the Banque de France. There is also heterogeneity among the different subsectors of the manufacturing sector: the food industry has the

\footnotetext{
${ }^{12}$ This technique is broadly adopted for estimating firms' productivity in the literature. See, for example, Van Beveren (2012) for a detailed overview of the existing techniques to estimate total factor productivity at the establishment level.

${ }^{13}$ French classification of activities (NAF Rev. 2) is the national statistical classification of activities.
} 
Table 1 Descriptive statistics, failure, 2001-2012

\begin{tabular}{|c|c|c|c|c|c|c|}
\hline & \multicolumn{3}{|c|}{ Food industry } & \multicolumn{3}{|c|}{$\begin{array}{l}\text { Manufacturing industry } \\
\text { (excluding food industry) }\end{array}$} \\
\hline & $\begin{array}{l}\text { No } \\
\text { failure }\end{array}$ & Failure & $\begin{array}{l}\text { Percentage } \\
\text { in total obs. }\end{array}$ & $\begin{array}{l}\text { No } \\
\text { failure }\end{array}$ & Failure & $\begin{array}{l}\text { Failure as a } \\
\text { percentage } \\
\text { in total obs. }\end{array}$ \\
\hline Number of firm-year obs. & 74,913 & 650 & 0.8 & 417,575 & 8402 & 2.0 \\
\hline \multicolumn{7}{|l|}{ Proportion in each category $(\%)$} \\
\hline SMEs & 0.89 & 0.98 & 0.9 & 0.94 & 0.98 & 2.1 \\
\hline Of which independent SMEs & 0.45 & 0.59 & 1.1 & 0.39 & 0.53 & 2.7 \\
\hline Intermediate-size and large firm & 0.11 & 0.02 & 0.2 & 0.06 & 0.02 & 0.8 \\
\hline Very small firm & 0.28 & 0.44 & 1.3 & 0.29 & 0.44 & 3.0 \\
\hline Small firm & 0.18 & 0.24 & 1.2 & 0.23 & 0.23 & 2.0 \\
\hline Medium firm & 0.20 & 0.19 & 0.8 & 0.22 & 0.19 & 1.7 \\
\hline Large firm & 0.34 & 0.13 & 0.3 & 0.25 & 0.14 & 1.1 \\
\hline Young firm (less than 5 years) & 0.05 & 0.07 & 1.2 & 0.05 & 0.08 & 3.0 \\
\hline Age (5-10 years) & 0.13 & 0.21 & 1.3 & 0.14 & 0.2 & 2.9 \\
\hline Age (more than 10 years) & 0.82 & 0.72 & 0.7 & 0.81 & 0.72 & 1.8 \\
\hline Bad BDF rating & 0.05 & 0.27 & 4.8 & 0.05 & 0.17 & 7.0 \\
\hline $\begin{array}{l}\text { Food products and beverages } \\
\text { of which meat products }\end{array}$ & $\begin{array}{l}1 \\
0.24\end{array}$ & $\begin{array}{l}1 \\
0.40\end{array}$ & $\begin{array}{l}0.8 \\
1.4\end{array}$ & & & \\
\hline Textiles, wearing apparel etc. & & & & 0.07 & 0.14 & 3.6 \\
\hline Wood, paper, coke and refined petrol & & & & 0.15 & 0.16 & 2.1 \\
\hline $\begin{array}{l}\text { Chemicals; other non-metallic } \\
\text { products }\end{array}$ & & & & 0.18 & 0.1 & 1.2 \\
\hline Basic, fabricated metals & & & & 0.24 & 0.24 & 2.0 \\
\hline $\begin{array}{l}\text { Computers; machinery, other } \\
\text { transport }\end{array}$ & & & & 0.19 & 0.18 & 2.0 \\
\hline $\begin{array}{l}\text { Furniture, machinery, other } \\
\text { manufacturing }\end{array}$ & & & & 0.17 & 0.18 & 2.2 \\
\hline
\end{tabular}

For bankrupt firms without balance sheet provided to the Banque de France for the year of their bankruptcy, we assume that their size category and sector are the same as in the last available balance sheet in Banque de France databases at most 3 years before their bankruptcy. Source: Fiben Bilan and firms' bankruptcy database, Banque de France

Independent SME not subsidiary of a corporate group, very small firm total assets $\leq 1$ million euros, small firm total assets one million to two million euros, medium firm total assets two million to five million euros, large firm total assets $>5$ million euros

lowest bankruptcy rate. Bankruptcy cases were declared more often in the basic and fabricated metals industry.

Table 2 provides the descriptive statistics on healthy firms and firms that went bankrupt. In the latter case, we separately consider observations corresponding to the year of failure and observations from 1 to 3 years before the bankruptcy. Bankruptcy is not a sudden event for firms but is rather the end of a trajectory experienced by firms that is significantly different from a healthy firm's life trajectory. As our descriptive statistics indicate, even 3 years before the bankruptcy event, these firms' economic and financial situations show signs of difficulties and different behaviors compared to their healthy counterparts.

Bankrupt firms are, as expected, less productive than healthy ones. Moreover, productivity begins to deteriorate
3 years before the failure, indicating the "shadow of death" effect as described in the firm demography literature. Furthermore, bankrupt firms also experience difficulties with respect to profits. Even 3 years before bankruptcy, these firms are less profitable than healthy firms. The worsening of bankrupt firms' economic situation is also reflected in the evolution of their financial structure. As these firms experience difficulties, the demand for external financing increases. Therefore, bankruptcy is characterized by a heavy debt burden. Firms close to bankruptcy may have greater demand for credit to cover their temporary financial difficulties rather than for investment projects. Indeed, in the year of the failure, for example, the average short-term debt is approximately two times higher than it is for healthy firms. 
Table 2 Descriptive statistics, main variables, and full sample, 2001-2012

\begin{tabular}{|c|c|c|c|c|c|c|c|c|}
\hline & \multicolumn{4}{|c|}{ Food industry } & \multicolumn{4}{|c|}{$\begin{array}{l}\text { Manufacturing industry } \\
\text { (excluding food industries) }\end{array}$} \\
\hline & Mean & Q1 & Median & Q3 & Mean & Q1 & Median & Q3 \\
\hline \multicolumn{9}{|l|}{ TFP } \\
\hline Year of the failure & 3.59 & 3.37 & 3.62 & 3.86 & 3.42 & 3.07 & 3.49 & 3.85 \\
\hline 1 year before & 3.7 & 3.45 & 3.71 & 3.99 & 3.64 & 3.32 & 3.69 & 4.02 \\
\hline 2 years before & 3.81 & 3.56 & 3.82 & 4.08 & 3.74 & 3.42 & 3.78 & 4.09 \\
\hline 3 years before & 3.89 & 3.64 & 3.87 & 4.13 & 3.78 & 3.46 & 3.81 & 4.12 \\
\hline Past & 3.85 & 3.61 & 3.83 & 4.1 & 3.81 & 3.51 & 3.83 & 4.12 \\
\hline No failure & 4.19 & 3.84 & 4.14 & 4.48 & 4.04 & 3.70 & 4.02 & 4.34 \\
\hline \multicolumn{9}{|l|}{ Cost of credit } \\
\hline Year of the failure & 0.07 & 0.03 & 0.06 & 0.07 & 0.09 & 0.04 & 0.07 & 0.12 \\
\hline 1 year before & 0.07 & 0.04 & 0.06 & 0.08 & 0.09 & 0.05 & 0.07 & 0.11 \\
\hline 2 years before & 0.07 & 0.04 & 0.06 & 0.08 & 0.09 & 0.05 & 0.07 & 0.11 \\
\hline 3 years before & 0.07 & 0.04 & 0.06 & 0.08 & 0.09 & 0.05 & 0.07 & 0.11 \\
\hline Past & 0.07 & 0.04 & 0.06 & 0.08 & 0.09 & 0.05 & 0.07 & 0.11 \\
\hline No failure & 0.05 & 0.03 & 0.05 & 0.07 & 0.07 & 0.04 & 0.05 & 0.08 \\
\hline \multicolumn{9}{|l|}{ Bank debt/total assets } \\
\hline Year of the failure & 0.27 & 0.08 & 0.23 & 0.43 & 0.28 & 0.09 & 0.23 & 0.42 \\
\hline 1 year before & 0.33 & 0.14 & 0.30 & 0.48 & 0.28 & 0.11 & 0.24 & 0.41 \\
\hline 2 years before & 0.29 & 0.12 & 0.27 & 0.43 & 0.26 & 0.1 & 0.22 & 0.38 \\
\hline 3 years before & 0.29 & 0.13 & 0.25 & 0.42 & 0.24 & 0.08 & 0.20 & 0.35 \\
\hline Past & 0.3 & 0.14 & 0.27 & 0.43 & 0.25 & 0.1 & 0.21 & 0.36 \\
\hline No failure & 0.21 & 0.06 & 0.17 & 0.32 & 0.17 & 0.03 & 0.11 & 0.25 \\
\hline \multicolumn{9}{|c|}{ Short-term bank debt/total assets } \\
\hline Year of the failure & 0.06 & 0.00 & 0.03 & 0.10 & 0.08 & 0.00 & 0.04 & 0.12 \\
\hline 1 year before & 0.08 & 0.00 & 0.05 & 0.14 & 0.10 & 0.01 & 0.07 & 0.16 \\
\hline 2 years before & 0.08 & 0.00 & 0.05 & 0.13 & 0.10 & 0.00 & 0.06 & 0.15 \\
\hline 3 years before & 0.08 & 0.00 & 0.05 & 0.12 & 0.08 & 0.00 & 0.04 & 0.13 \\
\hline Past & 0.09 & 0.01 & 0.06 & 0.13 & 0.11 & 0.01 & 0.06 & 0.16 \\
\hline No failure & 0.03 & 0.00 & 0.0 & 0.04 & 0.03 & 0.00 & 0.00 & 0.03 \\
\hline \multicolumn{9}{|l|}{ Profitability } \\
\hline Year of the failure & -0.06 & -0.18 & -0.05 & 0.05 & -0.1 & -0.23 & -0.07 & 0.04 \\
\hline 1 year before & -0.03 & -0.13 & -0.01 & 0.07 & -0.02 & -0.12 & 0.00 & 0.09 \\
\hline 2 years before & 0.02 & -0.05 & 0.03 & 0.1 & 0.04 & -0.05 & 0.05 & 0.14 \\
\hline 3 years before & 0.06 & 0 & 0.06 & 0.12 & 0.08 & -0.01 & 0.08 & 0.16 \\
\hline Past & 0.10 & 0.02 & 0.09 & 0.18 & 0.11 & 0.02 & 0.09 & 0.18 \\
\hline No failure & 0.13 & 0.05 & 0.11 & 0.19 & 0.18 & 0.06 & 0.14 & 0.25 \\
\hline
\end{tabular}

Note: The row "Past" corresponds to the variables defined as the mean of their past values at most 3 years before bankruptcy. Source: Fiben Bilan and firms' bankruptcy database, Banque de France, and authors' calculations
Higher financial charges are associated with bankruptcy. On average, the cost of credit is substantially higher for bankrupt firms during the year of the failure. On the one hand, this high cost reflects the nature of the relationship between default risk and the interest rate set by the bank. A firm's ex ante risk level is the primary factor in the cost of credit granted by the bank. On the other hand, these firms are also penalized by a higher cost of credit 3 years before the failure. This situation can lead firms into bankruptcy even if they are economically viable.

Table 2 also reveals differences between food industry firms and other manufacturing firms. There is a slight observed gap in productivity between food and manufacturing firms for both healthy firms and bankrupt firms. In particular, bankrupt food industry firms are more productive than bankrupt firms in other manufacturing sectors. On average, 
they are also less penalized by high credit costs. Moreover, food industry firms are more dependent on bank financing, especially for long-term financing.

\section{Econometric modeling and results}

The econometric analysis is based on a binary dependent variable model for the occurrence of the failure. This model raises a technical difficulty because the proportion of bankrupt companies that provided balance sheet data for the year of failure is very low $(0.5 \%$ of total observations) during the period 2001-2012. Even after accounting for the information gathered at most 3 years before the failure, this proportion remains low compared to that of healthy firms (only $2 \%$ ). The estimation is problematic when considering a binary dependent variable model for the occurrence of the failure. A model with a constant as the only explanatory variable can systematically predict non-bankruptcy. In other words, such a model can perfectly explain nearly $99 \%$ of the values of the dependent variable. However, this model does not provide any information to characterize the failure. A problem in statistical studies based on data on rare events is that the econometric estimation procedures may significantly underestimate the probability of their occurrence. To address this problem, Manski and Lerman (1977) propose using endogenous stratification, choice-based sampling. This technique is intended to overrepresent the rare event, which in our case is the bankruptcy of firms in the sample. The estimation is then obtained using a weighted endogenous sampling maximum-likelihood method. Suppose $Q_{1}$ is the proportion of bankrupt companies in the initial sample and $H_{1}$ is the proportion of bankrupt companies in the sample chosen by the econometrician for implementing endogenous sampling. Similarly, we define $Q_{0}=1-Q_{1}$ and $H_{0}=1-H_{1}$ for healthy firms.

The weighted endogenous sampling maximum-likelihood is defined as follows:

$$
\log L=\sum_{i=1}^{N} w_{i} \log F\left(q_{i}\left(\alpha_{i}+X_{i}^{\prime} \beta\right)\right)
$$

w i t h $\quad w_{i}=$ Bankruptcy $\frac{Q_{1}}{H_{1}}+(1-$ Bankruptcy $) \frac{Q_{0}}{H_{0}}$ a n d $q_{i}=2$ Bankruptcy -1 . Bankruptcy is a binary variable that takes the value 1 if the company is in bankruptcy and 0 otherwise. This variable is determined by the latent variable Bankruptcy ${ }^{*}$ which is a function of the explanatory variables (denoted $X$ ) for the occurrence of the failure. We have the following:

$$
\text { Bankruptcy }_{i t}^{*}=X_{i t}^{\prime} \beta+\alpha_{i}+\epsilon_{i t}
$$

and

Bankruptcy $_{i t}= \begin{cases}1, & \text { if Bankruptcy } \\ 0, & \text { otherwise }\end{cases}$

where $\alpha_{i}$ is the individual unobserved effect, and $\epsilon_{i t}$ is the model error term.

Thus, we must compute the weights $w$. We estimate a model in which the probability of bankruptcy during year $t$ is explained exclusively by the past performance or characteristics of the firm at $t-1, t-2$, and $t-3$. The model has the following form:

$\operatorname{Prob}\left(\right.$ Bankruptcy $\left._{i t} \mid X_{i, \text { past }}, \quad \beta, \alpha_{i}\right)=F\left(\alpha_{i}+X_{i, \text { past }}^{\prime} \beta\right)$

where $X_{i, \text { past }}^{\prime}$ is the mean of the past values of $X$ over at most 3 years $\left(X_{i, t-1}, X_{i, t-2}, X_{i, t-3}\right)$. The reason for considering this specification for our bankruptcy model is twofold. First, as we have observed from the descriptive statistics, the first bankruptcy signals appear up to 3 years before the failure, and the past performance or the past characteristics of the firm can explain its current situation. Second, a large majority of bankrupt firms did not provide their balance sheet data at the time of their failure. Thus, the scarce data from the year of the failure would substantially restrict the sample. According to our economic model, the drivers of bankruptcy are low productivity (TFP), a high cost of credit, a high bank debt level, firm age, and size. Our regression also includes annual and sectoral dummies, which can capture the impact of the macroeconomic environment and firms' entry rate as a measure of competition in a given sector. We estimate a probit model using pooled data with panel-robust standard errors.

The firm demography literature broadly opts for duration analysis in bankruptcy analysis, as it best controls for the change in risk prior to bankruptcy. As we described above, our analysis relies on a probabilistic model of bankruptcy in the context of binary dependent variable modeling. This choice was made for two reasons. First, according to our economic model, we have adopted an endogenous exit definition (at each period, firms decide to exit or stay by following a certain exit rule). Therefore, we consider the exit or bankruptcy to be a binary choice (exit vs. stay) for each firm in each period. Second, our model addresses the evolutionary nature of bankruptcy by considering the past values of the explanatory variables (the mean of lagged values up to three periods before period $t$ ). Moreover, firm age, as included in our model, is an indicator of the duration of firm activity and allows us to approximate a duration analysis approach to bankruptcy under certain conditions.

Another econometric issue related to our model is the possible endogeneity of the cost of credit and the share of bank credit in total assets. Indeed, banks charge riskier firms higher rates given the probability that they will be unable to honor the 
debt contract. A potential instrumental variable to address this endogeneity is the average cost of credit in sectors other than the sector in question, calculated by grouping firms by size and debt level for each year in our analysis period. Assuming that the credit market is identical for firms in all sectors, banks should employ a similar interest rate setting policy for firms in all sectors. Obviously, the credit costs of a firm in one sector will be correlated with the credit cost of a firm in another sector with similar characteristics (size, credit demand), but it will not be correlated with the bankruptcy risk of firms in other sectors. We propose an identic construction of the other instrumental variable for bank credit share. To address the endogeneity problem, we use a two-step approach based on a control function from Rivers and Vuong (1988). The twostep estimation procedure is as follows. We estimate an ordinary least squares (OLS) regression of the cost of credit on instrumental variables (by accounting for possible firm effects using the Mundlak approach), and we retain the residuals. In the second step, we estimate our probit regression of bankruptcy by including all exogenous variables, the cost of credit, and the estimated residuals as explanatory variables. Table 10 in Appendix provides the results of the econometric model with the estimated residuals. On the one hand, the estimated residual of the cost of credit is not significant. On the other hand, the correlation between the instrumental variable and the cost of credit is very high (Table 11 in Appendix), so this is not likely due to the weakness of the instrumental variable. We conclude that there is no endogeneity issue of the cost of credit. Indeed, the cost of credit we use consists of its past values. Given the acceptance of the exogeneity of the cost of credit, Table 3 provides the econometric results based on the model with only the instrumental variable for bank credit/total assets variable calculated as the average bank credit in other sectors than the sector of the firm.

Table 3 resumes our estimation results corresponding to three different specifications: the columns (1), (2), and (3) present, respectively, the estimation results of model (1) on the sample of food industry, (2) on the sample of other manufacturing industry, and (3) on the sample of manufacturing industry with all sub-sectors. The parameter signs are similar between these three models. ${ }^{14}$

As expected, younger and smaller firms are more likely to go bankrupt. As a proxy for firm experience, firms that were active for more than 10 years appear to be less risky. Our model also confirms that small firms are more vulnerable to bankruptcy risk than large firms. As expected and in accordance with the theoretical literature, productivity has a negative and significant impact on bankruptcy (Table 3). Firms with high productivity are less likely to go bankrupt. The

\footnotetext{
${ }^{14}$ Moreover, a likelihood ratio test shows that model (1) and model (3) are not different and the same conclusions on parameter estimates can be maintained for food industry and overall manufacturing firms.
}

deterioration of firm productivity can be interpreted as a sign of possible bankruptcy, even up to 3 years before the bankruptcy event. A higher cost of credit and a higher debt burden place firms at a higher risk of bankruptcy. We find a positive and significant impact of the cost of credit on bankruptcy (see model (1), column (1) in Table 3). By controlling for economic performance using the TFP level, firms with higher borrowing costs are more likely to go bankrupt. Compared to the productivity parameter estimate, we find a relatively weaker role for firm financial variables in the occurrence of bankruptcy. These results are compatible with previous studies considering a similar model. For example, based on a different definition of and empirical framework for firm exit, Blanchard et al. (2012) report a significantly negative coefficient of productivity in a probit regression of firm exit (close to 0.17 ) on a sample of French food industry firms, and Carneiro et al. (2013) estimate a standard firm failure probit model and find a negative and significant coefficient for firm TFP (approximately 0.29). These authors also show that higher firm-level interest rates and higher debt levels are associated with higher probabilities of firms shutting down.

We consider also food industry bankrupt firms' behavior before and after 2010. Table 4 shows that the parameter estimates have not changed after 2010. It allows us to think that the dramatic increase of bankruptcies is not due to the change of the impact of firm's economic or financial characteristics. Figures 2 and 3 in Appendix show the evolution of some economic indicators by comparing food industries and other manufacturing industries. This analysis allows us to propose the following possible explanation of bankruptcy patterns' differences between these two sectors. As the turnover of food industries decreases slightly during the crisis and value added increases considerably during the same period, we can conclude that the main reason of food industries resilience during the 2008-2009 crisis is due to the favorable evolution of factors linked to the intermediate consumption. Concerning the period 2010-2012, as we do not found a worsening of the impact of financial conditions, other factors can explain these differences such as competitiveness issues, the cut of subsidies, etc.. These hypotheses need to be confirmed in a framework of empirical analysis and are out of the scope of our paper.

The food industry appears to be the least risky manufacturing industry sub-sector. Indeed, the predicted bankruptcy rate in the food industry is half the one in other manufacturing sectors (Table 5). This result confirms the low proportion of bankrupt firms in the food industry, as seen in our descriptive analysis. The bankruptcy risk for very small and very young food industry firms is nearly half that to very small and very young firms, respectively, in other manufacturing industries. Our model confirms the differences in the evolution of bankruptcy risk during the crisis and after the crisis for the food industries and for other manufacturing industries. Indeed, 
Table 3 Parameter estimates, probit regression of firm bankruptcy using WEML on choice-based samples, 2001-2012

\begin{tabular}{|c|c|c|c|}
\hline $\operatorname{mean}\left(X_{i, t-1}, X_{i, t-2}, X_{i, t-3}\right)$ & Food industry (1) & $\begin{array}{l}\text { Manufacturing industry } \\
\text { (excluding food industry) (2) }\end{array}$ & $\begin{array}{l}\text { Manufacturing industry } \\
\text { (all sectors) (3) }\end{array}$ \\
\hline TFP & $-0.429 * * *(0.039)$ & $-0.323 * * *(0.011)$ & $-0.328 * * *(0.010)$ \\
\hline Cost of credit & $0.031 * * *(0.003)$ & $0.027 * * *(0.001)$ & $0.027 * * *(0.001)$ \\
\hline Bank credit/total assets & $0.009 * * *(0.001)$ & $0.013 * * *(0.000)$ & $0.013^{* * *}(0.000)$ \\
\hline Age (less than 5 years) & ref. & ref. & ref. \\
\hline Age (5-10 years) & $-0.060(0.064)$ & $-0.138 * * *(0.020)$ & $-0.131 * * *(0.019)$ \\
\hline Age (more than 10 years) & $-0.180 * *(0.057)$ & $-0.331 * * *(0.017)$ & $-0.318 * * *(0.016)$ \\
\hline Very small firm & ref. & ref. & ref. \\
\hline Small firm & $-0.029(0.040)$ & $-0.134 * * *(0.013)$ & $-0.126^{* * *}(0.012)$ \\
\hline Medium firm & $-0.071(0.044)$ & $-0.162 * * *(0.013)$ & $-0.155 * * *(0.013)$ \\
\hline Large firm & $-0.203 * * *(0.049)$ & $-0.179 * * *(0.015)$ & $-0.184 * * *(0.014)$ \\
\hline Electric, computer and electronic products etc. & & ref. & ref. \\
\hline Food industry & & & $-0.410 * * *(0.020)$ \\
\hline Transport equipment & & $-0.048(0.029)$ & $-0.045(0.029)$ \\
\hline Other manufacturing & & $-0.153 * * *(0.014)$ & $-0.152 * * *(0.014)$ \\
\hline Constant & $-0.986 * * *(0.175)$ & $-0.973 * * *(0.050)$ & $-0.959 * * *(0.048)$ \\
\hline Annual dummies & Yes & Yes & Yes \\
\hline IV average bank credit in other sectors & Yes & Yes & Yes \\
\hline Number of obs. & 31,583 & 191,019 & 222,602 \\
\hline Number of firms & 3545 & 23,444 & 26,989 \\
\hline $\log L$ & -1527.0 & $-17,414.3$ & $-18,960.0$ \\
\hline $\log L$ for null model & -1658.6 & $-18,687.1$ & $-20,452.0$ \\
\hline Wald test, chi-square & 537.4 & 4739.3 & 5470.9 \\
\hline Hosmer-Lemeshow chi-square $(18)($ number of groups $=20)$ & 11.03 & 14.44 & 21.82 \\
\hline WEML weight for non bankruptcy observations & 1.348 & 1.350 & 1.350 \\
\hline WEML weight for bankruptcy observations & 0.067 & 0.068 & 0.068 \\
\hline
\end{tabular}

Standard errors in parentheses. Panel-robust standard errors. Notes: Choice-based sampling is realized on observation level. Sampled firm-year observations were completed with available observations for the same panel from the original database. WEML weights were calculated for each year separately, but this table presents only the average WEML weights over our analysis period. Choice-based sampling is realized on the full sample of manufacturing industry. The sub-samples of the food industry and of the manufacturing industry (excluding food industry) were extracted from manufacturing industry choice-based sample. Comparison of parameter estimates between (1) and (2) $H_{0}: \beta_{\mathrm{tfp}}^{(1)}=\beta_{\mathrm{tfp}}^{(2)}, \quad$ chi-square $=7.58$, Prob $>$ chi-square $=0.00 . \quad H_{0}: \beta_{\text {CostCredit }}^{(1)}=\beta_{\text {CostCredit }}^{(2)}, \quad$ chi-square $=2.09$, Prob $>$ chi-square $=0.14$. $H_{0}: \beta_{\text {BankCredit }}^{(1)}=\beta_{\text {BankCredit }}^{(2)}$, chi-square $=5.25$, Prob $>$ chi-square $=0.02$

$I V$ instrumental variable, $W E M L$ weighted exogenous maximum likelihood weight

$* p<0.05, * * p<0.01, * * * p<0.001$

between 2008 and 2009, the predicted probability of bankruptcy decreases for food industry firms, whereas it increases by 0.8 percentage points for other manufacturing industries. Moreover, our predicted bankruptcy probability results correctly show that the bankruptcy risk increase in the food industry from 2010 until 2012.

Within the food industry, we observe significant differences in bankruptcy risk patterns for the meat industry compared to other food industries. Indeed, the meat industry is characterized by a higher probability of bankruptcy $(1.5 \%)$ relative to other food industries $(0.7 \%)$. The bankruptcy risk gap between these two sub-industries is more important for small and very small firms and for young firms. We also find that the increased bankruptcy risk in the food industry between 2010 and 2012 is mostly due to difficulties in the meat industry. This finding reflects the observed vulnerability of the French meat industry during the period 2010-2012. In 2013, the bankruptcy risk decreases slightly in the food industry but remains high relative to the average level for the period 20012010.

The predicted probability of bankruptcy is nearly $4.5 \%$ for manufacturing firms at the lowest productivity level (first percentile) (Table 6). The bankruptcy risk decreases considerably (up to 3-4 percentage points) for firms in the upper part of the productivity distribution. However, the effect of financial variables on bankruptcy risk appears to be less important than 
Table 4 Parameter estimates, probit regression of firm bankruptcy using WEML on choice-based samples, food industry, and other manufacturing industries (excluding food industries)

\begin{tabular}{|c|c|c|c|c|}
\hline & \multicolumn{2}{|l|}{ Food industry } & \multicolumn{2}{|c|}{$\begin{array}{l}\text { Other manufacturing industries } \\
\text { (excluding food industries) }\end{array}$} \\
\hline & Before 2010 (1) & After 2010 (2) & Before 2010 (3) & After 2010 (4) \\
\hline TFP & $-0.397 * * *(0.045)$ & $-0.508 * * *(0.075)$ & $-0.315 * * *(0.012)$ & $-0.332 * * *(0.019)$ \\
\hline Cost of credit & $0.032 * * *(0.004)$ & $0.028 * * *(0.007)$ & $0.027 * * *(0.001)$ & $0.023 * * *(0.002)$ \\
\hline Bank credit/total assets & $0.009 * * *(0.002)$ & $0.008 * * *(0.002)$ & $0.013 * * *(0.000)$ & $0.011 * * *(0.001)$ \\
\hline Age (less than 5 years) & ref. & ref. & ref. & ref. \\
\hline Age (5-10 years) & $-0.088(0.071)$ & $0.060(0.147)$ & $-0.124 * * *(0.021)$ & $-0.257 * * *(0.048)$ \\
\hline Age (more than 10 years) & $-0.224 * * *(0.062)$ & $-0.008(0.136)$ & $-0.303 * * *(0.018)$ & $-0.536 * * *(0.041)$ \\
\hline Very small firm & ref. & ref. & ref. & ref. \\
\hline Small firm & $-0.010(0.049)$ & $-0.074(0.072)$ & $-0.131 * * *(0.014)$ & $-0.137 * * *(0.024)$ \\
\hline Medium firm & $-0.068(0.053)$ & $-0.088(0.078)$ & $-0.149 * * *(0.015)$ & $-0.181 * * *(0.026)$ \\
\hline Large firm & $-0.191 * * *(0.057)$ & $-0.236 *(0.096)$ & $-0.149 * * *(0.017)$ & $-0.237 * * *(0.030)$ \\
\hline Constant & $-1.099 * * *(0.201)$ & $-0.748 *(0.338)$ & $-1.144 * * *(0.055)$ & $-0.612 * * *(0.089)$ \\
\hline Annual dummies & Yes & Yes & Yes & Yes \\
\hline IV average bank credit in other sectors & Yes & Yes & Yes & Yes \\
\hline Number of obs. & 22,316 & 9267 & 141,627 & 49,392 \\
\hline Number of firms & 3331 & 2652 & 22,706 & 14,528 \\
\hline $\log L$ & -1083.9 & -441.6 & $-13,368.2$ & -4065.1 \\
\hline $\log L$ for null model & -1175.7 & -482.9 & $-14,302.5$ & -4375.1 \\
\hline Wald test, chi-square & 388.0 & 170.7 & 3452.7 & 1384.0 \\
\hline WEML weight for non bankruptcy observations & 1.363 & 1.309 & 1.365 & 1.309 \\
\hline WEML weight for bankruptcy observations & 0.068 & 0.066 & 0.069 & 0.065 \\
\hline
\end{tabular}

Standard errors in parentheses. Panel-robust standard errors. Notes: Choice-based sampling is realized on observation-level. Sampled firm-year observations were completed with available observations for the same panel from the original database. WEML weights were calculated for each year separately, but this table presents only the average WEML weights over our analysis period. Choice-based sampling is realized on the full sample of manufacturing industry. The sub-samples of the food industry and of the manufacturing industry (excluding food industry) were extracted from manufacturing industry choice-based sample

$I V$ instrumental variable, $W E M L$ weighted exogenous maximum likelihood weight

$* p<0.05, * * p<0.01, * * * p<0.001$

that of productivity. For example, for manufacturing firms charged an interest rate of approximately $9 \%$, bankruptcy risk would decrease by only 1 percentage point if they had no financial charges. The predicted bankruptcy rate also has a lower sensitivity to bank debt levels. For example, comparing firms with a bank debt level of approximately $5 \%$ of their total assets to those that are nearly ten times more indebted (44\% bank debt level), the predicted probability gap is only 2.5 percentage points. Only firms reporting an extreme upper level (90th percentile level and higher) of financial charges and bank debt levels exhibit a bankruptcy risk that is close to alarming (more than $3 \%$ ). Moreover, comparing the differences in the predicted probabilities of the three variables at their 10th and 90th percentile values, we demonstrate that firm productivity has a greater effect on bankruptcy risk. Indeed, for example, in the food industry, the probability of bankruptcy decreases by approximately 1 percentage point if productivity increases from the 10th percentile to the 90th percentile value. This contrast is lower when considering the cost of credit and the bank debt ratio (bankruptcy risk increases by 1.5 and 3 percentage points, respectively, in the case of a change from the 10th to the 90th percentile values).

We find also that the productivity effect is lower for food industry firms compared to other manufacturing firms. Indeed, the beneficial effect from food industry firms' productivity growth corresponds to a decrease in bankruptcy risk of only 1 percentage point (comparing predicted probabilities calculated at the 10th and 90th percentile values of TFP). This effect is more important in other manufacturing industries (for which bankruptcy risk decreases by approximately 1.73 percentage points). The comparison of marginal effects (Table 14 in Appendix) confirms these disparities. Indeed, a 1-point increase in TFP decreases the probability of bankruptcy by 1.21 and 0.82 , respectively, for food industry firms and other manufacturing firms. 
Table 5 Predicted adjusted probability of bankruptcy, \%

\begin{tabular}{|c|c|c|c|c|c|}
\hline & \multirow[t]{2}{*}{ Food industry } & \multicolumn{2}{|l|}{ From which } & \multirow{2}{*}{$\begin{array}{l}\text { Manufacturing industries } \\
\text { (excluding food industries) }\end{array}$} & \multirow{2}{*}{$\begin{array}{l}\text { Manufacturing industries } \\
\text { (all sectors) }\end{array}$} \\
\hline & & Meat industry & $\begin{array}{l}\text { Food industries } \\
\text { (excluding meat industry) }\end{array}$ & & \\
\hline Full sample & 0.955 & 1.532 & 0.772 & 2.144 & 1.978 \\
\hline Very small firm & 1.67 & 2.342 & 1.394 & 3.337 & 3.129 \\
\hline Small firm & 1.258 & 1.909 & 1.038 & 2.131 & 2.033 \\
\hline Medium firm & 0.89 & 1.263 & 0.767 & 1.773 & 1.663 \\
\hline Large firm & 0.343 & 0.641 & 0.273 & 1.163 & 1.006 \\
\hline Age (less than 5 years) & 2.13 & 2.962 & 1.84 & 4.069 & 3.846 \\
\hline Age (5-10 years) & 1.624 & 2.337 & 1.378 & 3.117 & 2.933 \\
\hline Age (more than 10 years) & 0.779 & 1.298 & 0.617 & 1.829 & 1.676 \\
\hline 2007 & 0.859 & 1.441 & 0.687 & 1.544 & 1.452 \\
\hline 2008 & 0.966 & 1.613 & 0.777 & 1.715 & 1.612 \\
\hline 2009 & 0.752 & 1.26 & 0.6 & 2.525 & 2.261 \\
\hline 2010 & 0.692 & 1.097 & 0.575 & 1.916 & 1.733 \\
\hline 2011 & 0.813 & 1.272 & 0.683 & 1.831 & 1.677 \\
\hline 2012 & 1.197 & 1.787 & 1.022 & 1.862 & 1.765 \\
\hline 2013 & 1.095 & 1.575 & 0.95 & 1.891 & 1.766 \\
\hline
\end{tabular}

Notes: This table presents adjusted prediction, i.e., the predicted value of the probability of bankruptcy, while holding all other variables at their observed value in the sample. We compared the predictions of bankruptcy probability for meat industry on different possible models by sample type, weighting type, and presence of dummy variable for meat industry. We chose among these predictions the most accurate prediction based on its closeness with the observed bankruptcy rate in the meat industry

Table 6 Predicted probability of bankruptcy (\%) at quantiles of continuous variables

\begin{tabular}{|c|c|c|c|c|c|c|}
\hline \multicolumn{7}{|l|}{ TFP } \\
\hline & \multicolumn{2}{|l|}{ Food industry } & \multicolumn{2}{|c|}{ Manufacturing industries (excluding food industries) } & \multicolumn{2}{|l|}{ Manufacturing industry } \\
\hline & TFP quantile & Predicted prob. & TFP quantile & Predicted prob. & TFP quantile & Predicted prob. \\
\hline p1 & 2.907 & 2.679 & 2.649 & 4.851 & 2.677 & 4.494 \\
\hline $\mathrm{p} 10$ & 3.556 & 1.393 & 3.340 & 3.065 & 3.366 & 2.808 \\
\hline p25 & 3.784 & 1.090 & 3.649 & 2.464 & 3.671 & 2.252 \\
\hline p50 & 4.072 & 0.791 & 3.963 & 1.959 & 3.977 & 1.790 \\
\hline p75 & 4.413 & 0.532 & 4.270 & 1.554 & 4.290 & 1.404 \\
\hline p90 & 4.790 & 0.336 & 4.600 & 1.201 & 4.627 & 1.071 \\
\hline p99 & 5.733 & 0.096 & 5.550 & 0.543 & 5.589 & 0.469 \\
\hline \multicolumn{7}{|c|}{ Cost of credit } \\
\hline & Cost of credit quantile & Predicted prob. & Cost of credit quantile & Predicted prob. & Cost of credit quantile & Predicted prob. \\
\hline p1 & 0.000 & 0.568 & 0.000 & 1.285 & 0.000 & 1.187 \\
\hline p10 & 0.021 & 0.678 & 0.026 & 1.522 & 0.026 & 1.402 \\
\hline p25 & 0.036 & 0.766 & 0.043 & 1.689 & 0.042 & 1.554 \\
\hline p50 & 0.051 & 0.861 & 0.062 & 1.905 & 0.060 & 1.748 \\
\hline p75 & 0.072 & 1.016 & 0.096 & 2.332 & 0.092 & 2.127 \\
\hline p90 & 0.106 & 1.318 & 0.148 & 3.155 & 0.143 & 2.869 \\
\hline p99 & 0.215 & 2.874 & 0.276 & 6.230 & 0.271 & 5.748 \\
\hline \multicolumn{7}{|c|}{ Bank debt/total assets } \\
\hline & Bank debt ratio quantile & Predicted prob. & Bank debt ratio quantile & Predicted prob. & Bank debt ratio quantile & Predicted prob. \\
\hline p1 & 0.000 & 0.496 & 0.000 & 1.025 & 0.000 & 0.945 \\
\hline p10 & 0.017 & 0.517 & 0.007 & 1.050 & 0.008 & 0.970 \\
\hline p25 & 0.073 & 0.592 & 0.046 & 1.193 & 0.049 & 1.108 \\
\hline p50 & 0.181 & 0.764 & 0.134 & 1.592 & 0.140 & 1.484 \\
\hline p75 & 0.330 & 1.074 & 0.273 & 2.438 & 0.282 & 2.274 \\
\hline p90 & 0.484 & 1.503 & 0.432 & 3.845 & 0.440 & 3.557 \\
\hline p99 & 0.758 & 2.635 & 0.767 & 8.964 & 0.765 & 8.033 \\
\hline
\end{tabular}

Note: This table presents adjusted prediction, i.e., the predicted value of the probability of bankruptcy at quantiles, while holding all variables at their observed value in the sample 
The effects of firms' financing conditions reveal different patterns for the two sectors. On the one hand, the probability of bankruptcy increases almost equally for food industries and other manufacturing industries if credit becomes costly (the change from the 10th to the 90th percentile values of credit cost in each group of firms, which corresponds to a variation in credit cost from 0.02 to 0.10 and to a variation in credit cost from 0.02 to 0.14 , respectively). On the other hand, a change in the bank debt level has a lower effect on bankruptcy risk for the food industry than for other manufacturing industries. Indeed, comparing the differences in the predicted probabilities between the 10th and the 90th percentile values for the bank debt ratio in each sector, our results show that the difference in the food industry is less than half the difference in other manufacturing industries $(0.5$ percentage points and 2.6 percentage points, respectively). When comparing marginal effects for financial variables between the two sectors (Table 14 in Appendix), we find that if the credit cost increases by 1 unit, food firms probability of bankruptcy increases by 0.08 percentage point which is very close to the marginal effect of the cost of credit calculated for other manufacturing industries. However, the marginal effect of bank credit variable is lower for food industries compared to the one obtained for other manufacturing firms. Thus, compared to other manufacturing industries, food industries appear to be more sensible to productivity shocks and less sensible to bank credit impact on their probability risk.

\section{Conclusion}

This study identifies the role of economic and financial variables in determining firm bankruptcy. We demonstrate that smaller and younger firms are the most vulnerable. Of the manufacturing sub-sectors, the food industry appears to be more resilient to bankruptcy risks: its predicted probability is half the one in other manufacturing sectors. The bankruptcy predictions based on our model confirm the dramatic increase in bankruptcy risk in the French food industry observed over the current period. We also show that among food industry sub-sectors, the meat industry was primarily responsible for the evolution of bankruptcy risk between 2010 and 2012 . According to our results, higher productivity reduces bankruptcy risk, whereas a higher cost of credit increases bankruptcy risk. These results suggest that the economic performance of firms is not the only determinant of firm success (i.e., continuing activity in the market); firms' financing constraints, such as higher borrowing costs, can also challenge firm survival. However, in relative terms, the productivity effect appears to be more important for bankruptcy risk than financial situation indicators. We observe smaller effects of firm financial characteristics (credit cost, bank debt level) on firms' bankruptcy risk. In contrast, productivity appears to have an important beneficial effect on bankruptcy risk reduction. These results suggest that policies designed to implement productivity improvement measures are the most efficient for reducing bankruptcy risk in the food industry or the manufacturing sector. In this case, firms' financing conditions only affect bankruptcy risk if firms finance projects intended to increase their productivity, such as investing in innovative machines and qualified workers.

Acknowledgments We are extremely grateful to Patrick Sevestre for his very helpful discussions and suggestions. We would also like to thank Elisabeth Kremp for her guidance and comments on an earlier version of this paper. The first author wishes to dedicate this paper to the memory of Jean-Pierre Huiban, her $\mathrm{PhD}$ co-supervisor, who unfortunately passed away during the course of preparing this paper. This research was improved by the comments from the participants at the internal seminar of Banque de France Companies' Directorate, the lunch seminar at Sciences Po, the INRA ALISS internal seminar, the Insolvency workshop at Université Paris Nanterre, ADRES conference in Paris, the SAEe conference in Palma de Mallorca, and the AAEA \& WAEA Joint Annual Meeting in San Francisco.

\section{Appendix 1: data description}

\section{Fiben Bilan database}

Fiben accounting data are extracted from the individual company accounts collected yearly through the branch network of the Banque de France (balance sheet and income statements). They are based on fiscal documents. The target population includes companies and natural and legal persons that are domiciled or have registered offices in France. A broad range of information includes accounting and financial data from the balance sheet and profit-and-loss account, for companies with a turnover of at least 750,000 euros or companies with bank debt exceeding 380,000 euros.

\section{Bankruptcy database}

The Banque de France manages a database of legal information pertaining to judgments handed down by a commercial or a civil court ruling over a commercial case. The information is gathered from a variety of sources, including journals of legal notices, registries of commercial courts, France's National Statistics Office (INSEE). In this study, the firm bankruptcy is defined as the start of the judicial reorganization or liquidation proceedings according to the French law. If a firm has entered two of these proceedings during our observation period, only the first collective insolvency proceedings are taken into account (Table 7). 
Table 7 Number of failures of business units in France, by sector

Year Manufacturing Food Electrical, Transport Other industry industry computer, equipment manufacturing electronic products, etc.

\begin{tabular}{llllll}
\hline 1998 & 5457 & 1225 & 502 & 70 & 3660 \\
1999 & 5465 & 1200 & 514 & 65 & 3751 \\
2000 & 4626 & 1093 & 467 & 67 & 3066 \\
2001 & 4375 & 1060 & 455 & 71 & 2860 \\
2002 & 4789 & 1031 & 481 & 63 & 3277 \\
2003 & 5037 & 1025 & 526 & 75 & 3486 \\
2004 & 4758 & 1078 & 461 & 62 & 3219 \\
2005 & 4507 & 1003 & 416 & 69 & 3088 \\
2006 & 4176 & 1037 & 380 & 66 & 2759 \\
2007 & 3745 & 1134 & 306 & 41 & 2305 \\
2008 & 3943 & 1176 & 290 & 69 & 2477 \\
2009 & 4593 & 1141 & 371 & 105 & 3081 \\
2010 & 4058 & 1193 & 310 & 75 & 2555 \\
2011 & 3914 & 1308 & 232 & 57 & 2374 \\
2012 & 3921 & 1388 & 256 & 91 & 2277 \\
2013 & 3565 & 1284 & 219 & 71 & 2062 \\
\hline
\end{tabular}

Source: Firms' bankruptcy database, Banque de France

\section{Sample description}

\section{Merging data from the balance sheet database (Fiben Bilan) and the firms' bankruptcy database}

The sample obtained by merging data from Fiben Bilan and the firm' bankruptcy database includes only a small number of bankrupt firms. One of the main reasons is that a company subject to a court-administered proceeding (reorganization or liquidation) does not always provide its balance sheet for the year of failure. Thus, we link the failure occurred during the specific year by mobilizing balance sheet data from previous years. In more than $80 \%$ of cases, companies do not provide data about their balance sheet during the year of failure, and almost $50 \%$ do not provide these data 1 year before their failure as well. Thus, we use data on the latest non-missing balance sheet collected as long as it relates to the firm's situation during the year of the firm failure or at most 3 years before the failure. It is a way to cover the low number of failure data and analyze the impact of the defined ratios on the bankruptcy at a time when these bankrupt companies still have a significant activity (see Table 8).

\section{Econometric sample construction}

The sample obtained from merging data from the balance sheet database (Fiben Bilan) and the firms' bankruptcy
Table 8 Bankruptcy observations in Fiben Bilan over the period 1998 2012, manufacturing sector

\begin{tabular}{lll}
\hline & $1998-2012$ & \\
\hline $\begin{array}{l}\text { Bankrupt firms with recent financial } \\
\text { statements at least once }\end{array}$ & 15,838 & $100 \%$ \\
$\quad$ at most 3 years before bankruptcy & 13,967 & $88 \%$ \\
Year of the failure & 3484 & $22 \%$ \\
1 year before the failure & 5563 & $35 \%$ \\
2 years before the failure & 3917 & $25 \%$ \\
3 years before the failure & 1003 & $6 \%$ \\
More than 3 years before the failure & 1871 & $12 \%$ \\
\hline
\end{tabular}

database was further modified for the empirical analysis. First, our econometric model continuous variables' outliers were dropped from the sample. To do that, we deleted all observations that are lower (higher) than the threshold value calculated as $Q 1-5 * \mathrm{IQR}(Q 3+5 * \mathrm{IQR})$ where $Q 1(Q 3)$ is the first (third) quartile and IQR is the interquartile range. Second, as we decided to use the information at most 3 years before bankruptcy, for each firm, new observations were completed for the missing years on the basis of the past available information concerning the variables that were used in our analysis. In particular, for bankrupt firms without balance sheet provided to the Banque de France for the year of their bankruptcy, we assume that their size category and sector are the same as in the last available balance sheet in Banque de France databases at most 3 years before their bankruptcy. Concerning the continuous variables, we calculated new variables, defined as the average of their past available observations at most 3 years before the bankruptcy. Concerning firms for which only one observation or two observations are available in the past at most 3 years before the bankruptcy, new variables are calculated respectively as equal to the 1 -year lagged observation or as the average of their two past available observations.

These new variables were particularly used in the econometric part. The table describes this new extended database (Table 9).

Table 9 Econometric sample (before choice-based sampling), 20012012

Food industry Manufacturing industry (excluding food industry)

\begin{tabular}{lll}
\hline Number of firms & 10,377 & 56,988 \\
Number of firm-year obs. & 75,620 & 417,467 \\
Failure & 650 & 8402 \\
No failure & 74,970 & 409,065 \\
\hline
\end{tabular}




\section{Bankruptcy rate and method of computation of bankruptcy rate in Fiben Bilan}

Companies that are subject to collective insolvency proceedings rarely provide the Banque de France with recent accounting documentation. We take into account this fact when calculating the failure rate using the database of firms' financial statements. We calculate the failure rate on a population of firms that have provided their balance sheet data during the previous 3 years to the year $N$. We select all the healthy firms on 1 January of year $N$ for which the data for previous 3 years are available in the database: $N-1, N-2$, or $N-3$. Then, we count, among these firms, those who start a judicial reorganization or liquidation between 1 January and 31 December of year $N$. The ratio of these two quantities is equal to the annual failure rate of the firms with a balance sheet available information during the past 3 years.

\section{Appendix 2: definition of variables}

TFP We have calculated TFP using Levinsohn and Petrin's (2003) method. It is one of the most commonly applied estimators when estimating total factor productivity at the establishment level.

Cost of credit: Interest expenses divided by financial debt Bank debt: Short-term bank credit and long-term bank loans

Firm size: We use two categories of firm size: small- or medium-sized enterprises (SMEs) and non-SMEs (intermediate-sized enterprises (ISEs) and large enterprises). The definition of these categories in this study is based on three criteria: number of employees, annual turnover, and balance sheet assets. The SMEs employ fewer than 250 people, and their annual sales do not exceed 50 million euros or their total assets do not exceed 43 million euros. The firms not corresponding to these criteria are considered as non-SMEs.

Subsidiary of a corporate group: A group is a set of companies (subsidiaries) interlinked through shareholdings and controlled by a single company.

Manufacturing industry: We consider four sub-sectors of manufacturing industry:

1. Food industry: manufacture of food products, beverages, and tobacco products.

2. Electrical, computers, electronic products, etc.: manufacture of electrical, computer, and electronic equipment; manufacture of machinery; manufacture of coke and refined petroleum products.

3. Transport equipment: manufacture of transport equipment.

4. Other manufacturing: manufacture of textiles, wood and paper products, chemicals, rubber and plastics products, basic metals, etc.

Manufacture of food industry: In this study, food industry includes the following sub-sectors: the processing and preserving of meat and production of meat products; the processing and preserving of fish, crustaceans, and mollusks; the processing and preserving of fruit and vegetables; the manufacture of vegetable and animal oils and fats; the manufacture of dairy products; the manufacture of grain mill products, starches, and starch products; the manufacture of bakery and farinaceous products; the manufacture of other food products; the manufacture of prepared animal feeds; the manufacture of beverages; and the manufacture of tobacco products.

\section{Appendix 3: French food industry: some economic indicators}

Fig. 2 Economic activity indicators, by sector $(1998=100)$ (a, b). Source: Fiben Bilan (Banque de France) and authors' calculations (a) Turnover

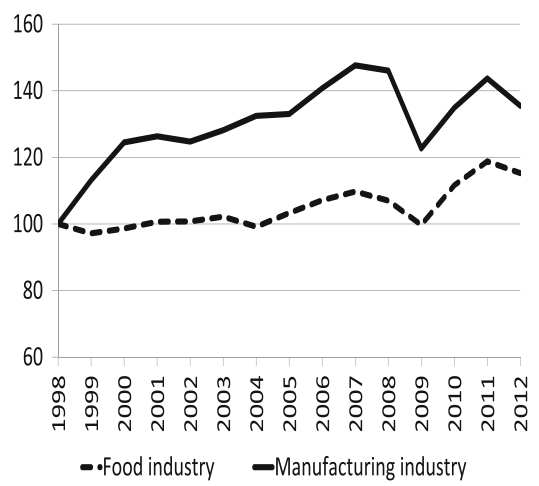

(b) Value added

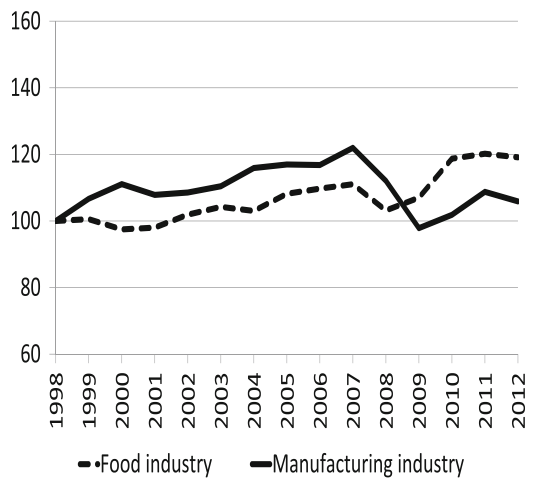




\section{Appendix 3: additional results}

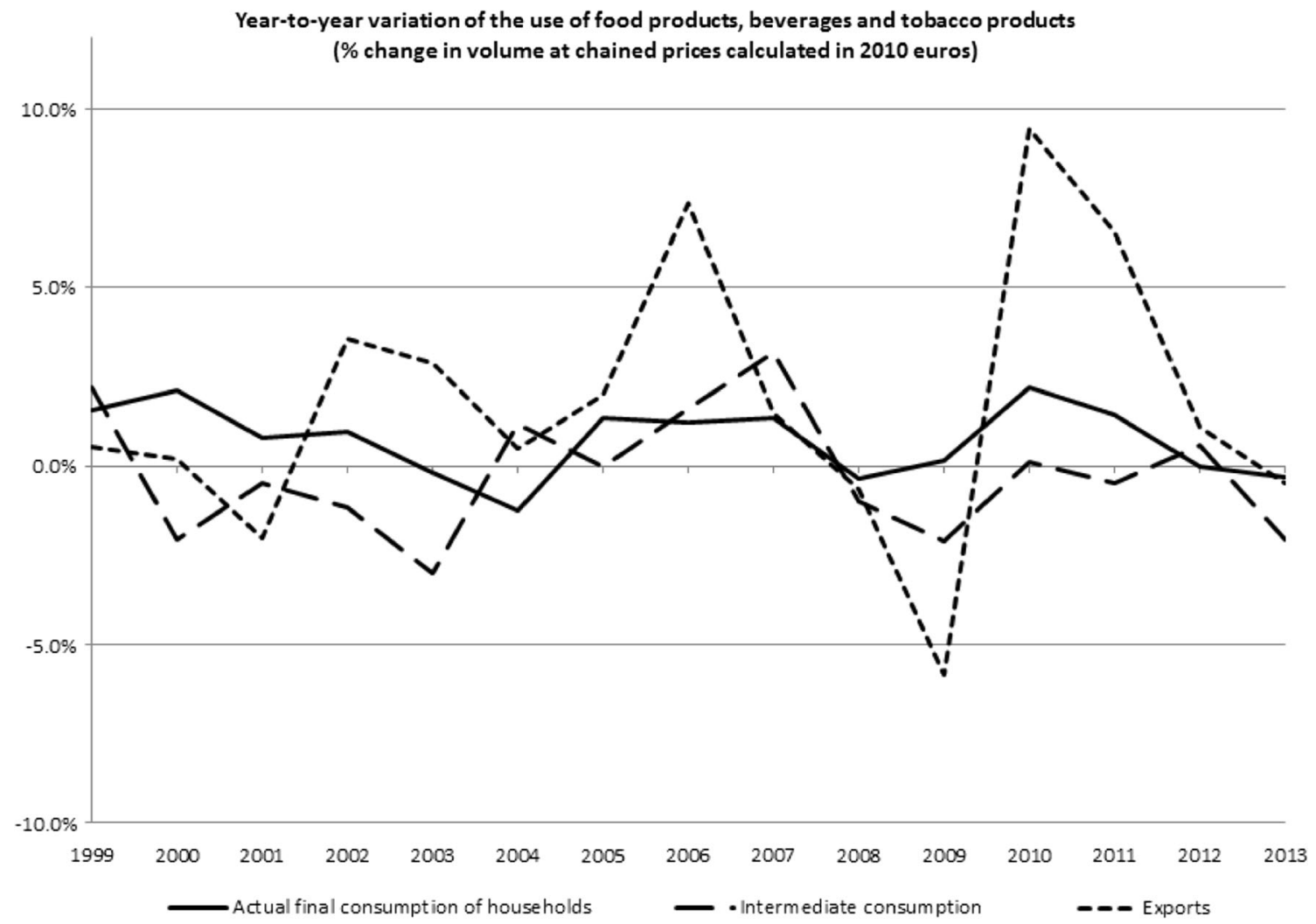

Fig. 3 Food industry demand perspectives: consumption of food products, beverages, and tobacco products. Source: INSEE (French Statistical Office) and authors' calculations

Table 10 Parameter estimates and probit regression of firm bankruptcy using WEML on choice-based samples, 2001-2012

\begin{tabular}{|c|c|c|c|}
\hline $\operatorname{mean}\left(X_{i, t-1}, X_{i, t-2}, X_{i, t-3}\right)$ & Food industry (1) & $\begin{array}{l}\text { Manufacturing industries } \\
\text { (excluding food industries) (2) }\end{array}$ & $\begin{array}{l}\text { Manufacturing industries } \\
\text { (all sectors) (3) }\end{array}$ \\
\hline TFP & $-0.431 * * *(0.040)$ & $-0.323 * * *(0.011)$ & $-0.328 * * *(0.010)$ \\
\hline Cost of credit & $0.026(0.017)$ & $0.029 * * *(0.005)$ & $0.028 * * *(0.004)$ \\
\hline Bank credit/total assets & $0.009 * * *(0.002)$ & $0.013 * * *(0.001)$ & $0.013 * * *(0.001)$ \\
\hline Age (less than 5 years) & ref. & ref. & ref. \\
\hline Age (5-10 years) & $-0.059(0.064)$ & $-0.139 * * *(0.020)$ & $-0.131 * * *(0.019)$ \\
\hline Age (more than 10 years) & $-0.179 * *(0.057)$ & $-0.332 * * *(0.017)$ & $-0.318 * * *(0.016)$ \\
\hline Very small firm & ref. & ref. & ref. \\
\hline Small firm & $-0.031(0.041)$ & $-0.134 * * *(0.013)$ & $-0.126 * * *(0.012)$ \\
\hline Medium firm & $-0.074(0.044)$ & $-0.161 * * *(0.014)$ & $-0.155 * * *(0.013)$ \\
\hline Large firm & $-0.209 * * *(0.050)$ & $-0.177 * * *(0.016)$ & $-0.183 * * *(0.015)$ \\
\hline Electric, computer and electronic products, etc. & & ref. & ref. \\
\hline Food industry & & & $-0.410 * * *(0.020)$ \\
\hline Transport equipment & & $-0.048(0.029)$ & $-0.045(0.029)$ \\
\hline Other manufacturing & & $-0.155 * * *(0.014)$ & $-0.153 * * *(0.014)$ \\
\hline Constant & $-0.926 * * *(0.246)$ & $-0.992 * * *(0.070)$ & $-0.965 * * *(0.067)$ \\
\hline Cost of credit residual IV & $0.611(1.753)$ & $-0.182(0.465)$ & $-0.054(0.447)$ \\
\hline Bank credit residual IV & $-0.290(0.222)$ & $-0.796 * * *(0.073)$ & $-0.760 * * *(0.070)$ \\
\hline
\end{tabular}


Table 10 (continued)

\begin{tabular}{llll}
\hline mean $\left(X_{i, t-1}, X_{i, t-2}, X_{i, t-3}\right)$ & Food industry (1) & $\begin{array}{l}\text { Manufacturing industries } \\
\text { (excluding food industries) (2) }\end{array}$ & $\begin{array}{l}\text { Manufacturing industries } \\
\text { (all sectors) (3) }\end{array}$ \\
\hline Annual dummies & Yes & Yes & Yes \\
Number of obs. & 31,583 & 191,019 & 222,602 \\
Number of firms & 3545 & 23,444 & 26,989 \\
Log $L$ & -1527.0 & $-17,414.3$ & $-18,960.0$ \\
Log $L$ for null model & -1658.6 & $-18,687.1$ & $-20,452.0$ \\
Wald test, chi-square & 537.2 & 4741.3 & 5472.1 \\
WEML weight for non bankruptcy observations & 1.348 & 1.350 & 1.350 \\
WEML weight for bankruptcy observations & 0.067 & 0.068 & 0.068 \\
\hline
\end{tabular}

Standard errors in parentheses. Panel-robust standard errors. Notes: Choice-based sampling is realized on observation-level. Sampled firm-year observations were completed with available observations for the same panel from the original database. WEML weights were calculated for each year separately, but this table presents only the average WEML weights over our analysis period. Choice-based sampling is realized on the full sample of manufacturing industry. The sub-samples of the food industry and of the manufacturing industry (excluding food industry) were extracted from manufacturing industry choice-based sample. Comparison of parameter estimates between (1) and (2) $H_{0}: \beta_{\mathrm{tfp}}^{(1)}=\beta_{\mathrm{tfp}}^{(2)}$, chi-square $=7.24$. $H_{0}$ $: \beta_{\text {CostCredit }}^{(1)}=\beta_{\text {CostCredit }}^{(2)}$, chi-square $=0.33 . H_{0}: \beta_{\text {BankCredit }}^{(1)}=\beta_{\text {BankCredit }}^{(2)}$, chi-square $=2.34$.

$I V$ instrumental variable, $W E M L$ weighted exogenous maximum likelihood weight

$* p<0.05, * * p<0.01, * * * p<0.001$

Table 11 Correlation matrix of variables with their possible instrumental variables (IVs)

\begin{tabular}{lllll}
\hline & Cost of credit & $\begin{array}{l}\text { IV average cost } \\
\text { of credit in other } \\
\text { sectors }\end{array}$ & $\begin{array}{l}\text { Bank credit/total } \\
\text { assets }\end{array}$ & $\begin{array}{l}\text { IV average bank } \\
\text { credit in other } \\
\text { sectors }\end{array}$ \\
\hline $\begin{array}{l}\text { Cost of credit } \\
\text { IV average cost of credit in other sectors }\end{array}$ & 0.33 & 1.00 & & \\
Bank credit/total assets & & & 1.00 & 1.00 \\
IV average bank credit in othersectors & & 0.70 & \\
\hline
\end{tabular}

Table 12 Parameter estimates and probit regression of firm bankruptcy using WEML on choice-based samples, manufacturing industry, 2001-2012

\begin{tabular}{|c|c|c|c|}
\hline & $\left(X_{i, t-1}\right)$ & $\left(X_{i, t-2}\right)$ & $\left(X_{i, t-3}\right)$ \\
\hline TFP & $-0.271 * * *(0.022)$ & $-0.234 * * *(0.021)$ & $-0.155 * * *(0.019)$ \\
\hline Cost of credit & $0.016 * * *(0.002)$ & $0.014 * * *(0.001)$ & $0.011 * * *(0.001)$ \\
\hline Bank credit/total assets & $0.012 * * *(0.001)$ & $0.008 * * *(0.001)$ & $0.008 * * *(0.001)$ \\
\hline Age (less than 5 years) & ref. & ref. & ref. \\
\hline Age $(5-10$ years $)$ & $-0.188 * * *(0.038)$ & $-0.239 * * *(0.034)$ & $-0.192 * * *(0.034)$ \\
\hline Age (more than 10 years) & $-0.277 * * *(0.030)$ & $-0.437 * * *(0.029)$ & $-0.412 * * *(0.029)$ \\
\hline Very small firm & ref. & ref. & ref. \\
\hline Small firm & $-0.045(0.033)$ & $-0.068 *(0.029)$ & $-0.078 * *(0.028)$ \\
\hline Medium firm & $-0.078 *(0.037)$ & $-0.102 * *(0.032)$ & $-0.205 * * *(0.029)$ \\
\hline Large firm & $-0.052(0.041)$ & $-0.114 * *(0.037)$ & $-0.241 * * *(0.033)$ \\
\hline Electrical, computer and electronic products etc. & ref. & ref. & ref. \\
\hline Food industry & $-0.487 * * *(0.054)$ & $-0.386 * * *(0.048)$ & $-0.313 * * *(0.045)$ \\
\hline Transport equipment & $-0.015(0.082)$ & $0.005(0.067)$ & $0.048(0.065)$ \\
\hline Other manufacturing & $-0.090 *(0.037)$ & $-0.045(0.033)$ & $-0.068 *(0.031)$ \\
\hline Constant & $-1.167 * * *(0.109)$ & $-0.761 * * *(0.098)$ & $-1.294 * * *(0.088)$ \\
\hline Annual dummies & Yes & Yes & Yes \\
\hline IV Average bank credit in other sectors & Yes & Yes & Yes \\
\hline
\end{tabular}

$$
\begin{aligned}
& -0.271 * * *(0.022) \\
& 0.016 * * *(0.002) \\
& 0.012 * * *(0.001) \\
& \text { ref. } \\
& -0.188 * * *(0.038) \\
& -0.277 * * *(0.030) \\
& \text { ref. } \\
& -0.045(0.033) \\
& -0.078 *(0.037) \\
& -0.052(0.041) \\
& \text { ref. } \\
& -0.487 * * *(0.054) \\
& -0.015(0.082) \\
& -0.090 *(0.037) \\
& -1.167 * * *(0.109) \\
& \text { Yes }
\end{aligned}
$$


Table 12 (continued)

\begin{tabular}{llll}
\hline & $\left(X_{i, t-1}\right)$ & $\left(X_{i, t-2}\right)$ & $\left(X_{i, t-3}\right)$ \\
\hline Number of obs. & 8915 & 10,003 & 12,760 \\
Number of firms & 4725 & 5494 & 7025 \\
Log $L$ & -911.5 & -1358.5 & -1414.8 \\
Log $L$ for null model & -975.7 & -1441.8 & -1495.0 \\
Wald test, chi-square & 644.5 & 778.2 & 807.9 \\
WEML weight for non bankruptcy observations & 1.434 & 1.617 & 1.474 \\
WEML weight for bankruptcy observations & 0.072 & 0.082 & 0.074 \\
\hline
\end{tabular}

Standard errors in parentheses. Panel-robust standard errors. Notes: Choice-based sampling is realized on observation-level. Sampled firm-year observations were completed with available observations for the same panel from the original database. WEML weights were calculated for each year separately, but this table presents only the average WEML weights over our analysis period. Choice-based sampling is realized on the full sample of manufacturing industry. The sub-samples of the food industry and of the manufacturing industry (excluding food industry) were extracted from the manufacturing industry choice-based sample

$I V$ instrumental variable, $W E M L$ weighted exogenous maximum likelihood weight

$* p<0.05, * * p<0.01, * * * p<0.001$

Table 13 Parameter estimates and probit regression of firm bankruptcy using WEML on choice-based samples, manufacturing industry, 2001-2012

\begin{tabular}{|c|c|c|c|}
\hline $\operatorname{mean}\left(X_{i, t-1}, X_{i, t-2}, X_{i, t-3}\right)$ & Without random effects (1) & With random effects (2) & With Mundlak variables (3) \\
\hline TFP & $-0.328 * * *(0.010)$ & $-0.484 * * *(0.019)$ & $-0.657 * * *(0.037)$ \\
\hline Cost of credit & $0.027 * * *(0.001)$ & $0.037 * * *(0.001)$ & $0.023 * * *(0.003)$ \\
\hline Bank credit/total assets & $0.013 * * *(0.000)$ & $0.019 * * *(0.001)$ & $0.025 * * *(0.002)$ \\
\hline Age (less than 5 years) & ref. & ref. & ref. \\
\hline Age $(5-10$ years $)$ & $-0.131 * * *(0.019)$ & $-0.110 * * *(0.024)$ & $-0.051(0.040)$ \\
\hline Age (more than 10 years) & $-0.318 * * *(0.016)$ & $-0.336 * * *(0.021)$ & $0.086(0.062)$ \\
\hline Very small firm & ref. & ref. & ref. \\
\hline Small firm & $-0.126 * * *(0.012)$ & $-0.171 * * *(0.018)$ & $-0.111 * * *(0.021)$ \\
\hline Medium firm & $-0.155 * * *(0.013)$ & $-0.206 * * *(0.019)$ & $-0.162 * * *(0.022)$ \\
\hline Large firm & $-0.184 * * *(0.014)$ & $-0.240 * * *(0.021)$ & $-0.237 * * *(0.026)$ \\
\hline Electric, computer and electronic products, etc. & ref. & ref. & ref. \\
\hline Food industry & $-0.410 * * *(0.020)$ & $-0.600 * * *(0.034)$ & $-0.281 * * *(0.036)$ \\
\hline Transport equipment & $-0.045(0.029)$ & $-0.070(0.043)$ & $0.003(0.052)$ \\
\hline Other manufacturing & $-0.152 * * *(0.014)$ & $-0.217 * * *(0.021)$ & $-0.090 * * *(0.024)$ \\
\hline Constant & $-0.959 * * *(0.048)$ & $-0.432 * * *(0.063)$ & $1139.140 * * *(17.191)$ \\
\hline Annual dummies & Yes & Yes & Yes \\
\hline IV average bank credit in other sectors & Yes & Yes & Yes \\
\hline Mundlak variables & No & No & Yes \\
\hline Number of obs. & 222,602 & 222,602 & 22,260 \\
\hline $\log L$ & $-18,960.0$ & $-34,596.5$ & $-13,789.0$ \\
\hline Wald test, chi-square & 5470.9 & 2797.1 & $13,326.1$ \\
\hline WEML weight for non bankruptcy observations & 1.350 & 1.350 & 1.350 \\
\hline WEML weight for bankruptcy observations & 0.068 & 0.068 & 0.068 \\
\hline
\end{tabular}

Standard errors in parentheses. Panel-robust standard errors. Notes: Choice-based sampling is realized on observation-level. Sampled firm-year observations were completed with available observations for the same panel from the original database. WEML weights were calculated for each year separately, but this table presents only the average WEML weights over our analysis period. Choice-based sampling is realized on the full sample of manufacturing industry. The sub-samples of the food industry and of the manufacturing industry (excluding food industry) were extracted from the manufacturing industry choice-based sample

$I V$ instrumental variable, WEML weighted exogenous maximum likelihood weight

$* p<0.05, * * p<0.01, * * * p<0.001$ 
Table 14 Marginal effects and probit regression of firm bankruptcy using WEML on choice-based samples, 2001-2012

\begin{tabular}{llll}
\hline mean $\left(X_{i, t-1}, X_{i, t-2}, X_{i, t-3}\right)$ & Food industry (1) & $\begin{array}{l}\text { Manufacturing industries } \\
\text { (excluding food industries) (2) }\end{array}$ & $\begin{array}{l}\text { Manufacturing industries } \\
\text { (all sectors) (3) }\end{array}$ \\
\hline TFP & & $-0.820^{* * *}(0.027)$ & $-0.844 * * *(0.027)$ \\
Cost of credit & $-1.221^{* * *}(0.113)$ & $0.068^{* * *}(0.002)$ & $0.070^{* * *}(0.002)$ \\
Bank credit/total assets & $0.089^{* * *}(0.010)$ & $0.034^{* * *}(0.001)$ & $0.033^{* * *}(0.001)$ \\
Age (less than 5 years) & $0.025^{* * *}(0.004)$ & ref. & $-0.313 * * *(0.044)$ \\
Age (5-10 years) & ref. & $-0.324^{* * *}(0.046)$ & $-0.786^{* * * *}(0.038)$ \\
Age (more than 10 years) & $-0.163(0.174)$ & $-0.805^{* * *}(0.039)$ & ref. \\
Very small firm & $-0.501^{* *}(0.155)$ & ref. & $-0.319 * * *(0.031)$ \\
Small firm & ref. & $-0.335^{* * *}(0.032)$ & $-0.395^{* * *}(0.033)$ \\
Medium firm & $-0.080(0.112)$ & $-0.406^{* * *}(0.034)$ & $-0.471^{* * *}(0.037)$ \\
Large firm & $-0.197(0.122)$ & $-0.450^{* * * *}(0.038)$ & ref. \\
Electric, computer and electronic products etc. & $-0.581^{* * *}(0.141)$ & ref. & $-1.071^{* * *}(0.054)$ \\
Food industry & & & $-0.111(0.072)$ \\
Transport equipment & & $-0.116(0.072)$ & $-0.380^{* * *}(0.034)$ \\
Other manufacturing & & $-0.382^{* * *}(0.034)$ & Yes \\
Annual dummies & Yes & Yes & Yes \\
IV average bank credit in other sectors & Yes & Yes & 222,602 \\
Number of obs. & 31,583 & 191,019 & \\
\hline
\end{tabular}

Standard errors in parentheses. Panel-robust standard errors. Notes: Choice-based sampling is realized on observation-level. Sampled firm-year observations were completed with available observations for the same panel from the original database. WEML weights were calculated for each year separately, but this table presents only the average WEML weights over our analysis period. Choice-based sampling is realized on the full sample of manufacturing industry. The sub-samples of the food industry and of the manufacturing industry (excluding food industry) were extracted from the manufacturing industry choice-based sample

$I V$ instrumental variable, $W E M L$ weighted exogenous maximum likelihood weight

$* p<0.05, * * p<0.01, * * * p<0.001$

Table 15 Descriptive statistics, main variables, and full sample, 2001-2012

\begin{tabular}{|c|c|c|c|c|c|c|}
\hline & \multicolumn{3}{|c|}{ Food industry } & \multicolumn{3}{|c|}{ Manufacturing industries (excl. food industries) } \\
\hline & \multirow[t]{2}{*}{ Mean } & \multicolumn{2}{|c|}{ Comparison of means } & \multirow[t]{2}{*}{ Mean } & \multicolumn{2}{|c|}{ Comparison of means } \\
\hline & & $T$ test & $p$ value & & $T$ test & $p$ value \\
\hline \multicolumn{7}{|l|}{ TFP } \\
\hline Year of the failure & 3.59 & -16.361 & 0.000 & 3.42 & -14.719 & 0.000 \\
\hline 1 year before & 3.7 & -15.424 & 0.000 & 3.64 & -12.407 & 0.000 \\
\hline 2 years before & 3.81 & -11.945 & 0.000 & 3.74 & -11.000 & 0.000 \\
\hline 3 years before & 3.89 & -10.691 & 0.000 & 3.78 & -9.814 & 0.000 \\
\hline No failure & 4.19 & & & 4.04 & & \\
\hline \multicolumn{7}{|l|}{ Cost of credit } \\
\hline Year of the failure & 0.07 & 8.210 & 0.000 & 0.09 & 13.088 & 0.000 \\
\hline 1 year before & 0.07 & 6.877 & 0.000 & 0.09 & 11.738 & 0.000 \\
\hline 2 years before & 0.07 & 6.942 & 0.000 & 0.09 & 9.761 & 0.000 \\
\hline 3 years before & 0.07 & 8.096 & 0.000 & 0.09 & 10.171 & 0.000 \\
\hline No failure & 0.05 & & & 0.07 & & \\
\hline \multicolumn{7}{|l|}{ Bank debt/total assets } \\
\hline Year of the failure & 0.27 & 12.265 & 0.000 & 0.28 & 16.938 & 0.000 \\
\hline 1 year before & 0.33 & 12.004 & 0.000 & 0.28 & 14.758 & 0.000 \\
\hline 2 years before & 0.29 & 8.754 & 0.000 & 0.26 & 15.807 & 0.000 \\
\hline 3 years before & 0.29 & 7.159 & 0.000 & 0.24 & 10.933 & 0.000 \\
\hline No failure & 0.21 & & & 0.17 & & \\
\hline
\end{tabular}

Note: Test of comparisons of means was conducted by comparing each category of bankruptcy lines with healthy firms' observations. Source: Fiben Bilan and firms' bankruptcy database, Banque de France, and authors' calculations 


\section{References}

Ackerberg D, Benkard L, Berry S, Pakes A (2007) Econometric tools for analyzing market outcomes. In: Heckman JJ, Leamer EE (eds) Handbook of econometrics, Elsevier, chapter 63, volume 6, Part A, $4171-4276$

Albuquerque R, Hopenhayn H (2004) Optimal lending contracts and firm dynamics. Rev Econ Stud 71(2):285-315

Aleksanyan L (2015) La situation économique et financière des entreprises agroalimentaires françaises (1998-2012). Econom Rural 349-350:125-147

Altman EI (1968) Financial ratios, discriminant analysis and the predictions of corporate bankruptcy. J Financ 23(4):589-609

Arellano C, Bai Y, Zhang J (2012) Firm dynamics and financial development. J Monet Econ 59(6):533-549

Avouyi-Dovi S, Horny G, Sevestre P (2012) Cost of funds, credit risk and bank loan interest rates in the crisis: what to micro data tell us?, work in progress, mimeo, Banque de France

Baily MN, Hulten C, Campbell D, Bresnahan T, Caves R (1992) Productivity dynamics in manufacturing plants. Brook Pap Econom Activ Microeconom 1992:187-267

Bartelsman EJ, Doms M (2000) Understanding productivity: lessons from longitudinal microdata. J Econ Lit 38(3):569-594

Bellone F, Musso P, Nesta L, Quéré M (2006) Productivity and market selection of French manufacturing firms in the nineties. Rev de l'OFCE 97(5):319-349

Blanchard P, Huiban J-P, Mathieu C (2012) The determinants of firm exit in the French food industries. Rev Agric Environ Stud 93(2):193-212

Boyer T, Blazy R (2014) Born to be alive? The survival of innovative and non-innovative French micro-start-ups. Small Bus Econ 42(4):669-683

Carneiro A, Portugal P, Varejão J (2013) Catastrophic job destruction, IZA discussion papers series no. 7670. Institute for the Study of Labor, Bonn, $38 \mathrm{p}$

Caves R (1998) Industrial organization and new findings on the turnover and mobility of firms. J Econ Lit 36(4):1947-1982
Cooley T, Quadrini V (2001) Financial markets and firm dynamics. Am Econ Rev 91(5):1286-1310

Dwyer D (1998) Technology locks, creative destruction, and non convergence in productivity levels. Rev Econ Dyn 1(2):430-473

Ericson R, Pakes A (1995) Markov-perfect industry dynamics: a framework for empirical work. Rev Econ Stud 62(1):53-82

Evans DS, Jovanovic B (1989) An estimated model of entrepreneurial choice under liquidity constraints. J Polit Econ 97(4):808-827

Fariñas JC, Ruano S (2005) Firm productivity, heterogeneity, sunk costs and market selection. Int J Ind Organ 23(7-8):505-534

Fougère D, Golfier C, Horny G, Kremp E (2013) Quel a été l'impact de la crise de 2008 sur la défaillance des entreprises ? Econom Stat 462(1):69-97

Hopenhayn H (1992) Exit, selection, and the value of firms. J Econ Dyn Control 16(3-4):621-653

Jovanovic B (1982) Selection and the evolution of industry. Econometrica 50(3):649-670

Kremp E, Sevestre P (2013) Did the crisis induce credit rationing for French SMEs? J Bank Financ 37(10):3757-3772

Levinsohn J, Petrin A (2003) Estimating production functions using inputs to control for unobservables. Rev Econ Stud 70(2):317-341

Manski CF, Lerman R (1977) The estimation of choice probabilities from choice based samples. Econometrica 45(8):1977-1988

Olley GS, Pakes A (1996) The dynamics of productivity in the telecommunications equipment industry. Econometrica 64(6):1263-1297

Osotimehin S, Pappadà F (2015) Credit frictions and the cleansing effect of recessions. Econ J. doi:10.1111/ecoj.12319

Rivers D, Vuong QH (1988) Limited information estimators and exogeneity tests for simultaneous probit models. J Econ 39(3):347-366

Roberts MJ, Tybout JR (1997) Producer turnover and productivity growth in developing countries. World Bank Res Obs 12(1):1-18

Stat Info (2013) Les défaillances d'entreprises, France, https://www. banque-france.fr/uploads/tx-bdfgrandesdates/Stat-info-defaillancesentreprises-janvier-2013.pdf, Janvier, Banque de France, 2 p

Van Beveren I (2012) Total factor productivity estimation: a practical review. J Econ Surv 26(1):98-128 